\title{
GUIDELINES
}

\section{Transfusion strategies in bleeding critically ill adults: a clinical practice guideline from the European Society of Intensive Care Medicine}

\author{
Alexander P. J. Vlaar ${ }^{*}$ (D), Joanna C. Dionne ${ }^{2,3,4,21}$, Sanne de Bruin ${ }^{1}$, Marije Wijnberge ${ }^{1,5}$, S. Jorinde Raasveld ${ }^{1}$, \\ Frank E. H. P. van Baarle ${ }^{1}$, Massimo Antonelli, ${ }^{6,7}$, Cecile Aubron ${ }^{8}$, Jacques Duranteau ${ }^{9}$, Nicole P. Juffermans ${ }^{10,11}$, \\ Jens Meier ${ }^{12}$, Gavin J. Murphy ${ }^{13}$, Riccardo Abbasciano ${ }^{13}$, Marcella C. A. Müller ${ }^{1}$, Marcus Lance ${ }^{14}$, \\ Nathan D. Nielsen ${ }^{15}$, Herbert Schöchl ${ }^{16,17}$, Beverley J. Hunt ${ }^{18}$, Maurizio Cecconi ${ }^{19,20}$ and Simon Oczkowski ${ }^{2,3,4}$
}

\begin{abstract}
Purpose: To develop evidence-based clinical practice recommendations regarding transfusion practices and transfusion in bleeding critically ill adults.

Methods: A taskforce involving 15 international experts and 2 methodologists used the GRADE approach to guideline development. The taskforce addressed three main topics: transfusion support in massively and non-massively bleeding critically ill patients (transfusion ratios, blood products, and point of care testing) and the use of tranexamic acid. The panel developed and answered structured guideline questions using population, intervention, comparison, and outcomes (PICO) format.
\end{abstract}

Results: The taskforce generated 26 clinical practice recommendations ( 2 strong recommendations, 13 conditional recommendations, 11 no recommendation), and identified 10 PICOs with insufficient evidence to make a recommendation.

Conclusions: This clinical practice guideline provides evidence-based recommendations for the management of massively and non-massively bleeding critically ill adult patients and identifies areas where further research is needed.

Keywords: Transfusion, Coagulopathy, Critically ill, Guideline, Intensive care, Plasma, Platelets, Red blood cells, Point of care, Tranexamic acid, Bleeding

\footnotetext{
*Correspondence: a.p.vlaar@amsterdamumc.nl

${ }^{1}$ Department of Intensive Care Medicine, Amsterdam UMC, Location

AMC, Room, C3-430, Meibergdreef 9, 1105 AZ Amsterdam, The Netherlands

Full author information is available at the end of the article

Alexander P. J. Vlaar and Joanna C. Dionne contributed equally.
}

\section{Introduction}

Patients admitted to the intensive care unit (ICU) frequently experience bleeding due to a variety of causes, with incidences of bleeding up to $50 \%$ reported in some ICU populations, and this in turn is associated with increased morbidity and mortality [1-3]. While transfusion of blood products is one of the cornerstones in treatment of bleeding critically ill patients, administration of blood products also carries risks, both theoretical and measurable.

\section{至 Springer}


Challenges exist in researching bleeding in critically ill patients, particularly with the varied definitions used to describe massive and non-massive bleeding. Massive bleeding by convention can be described as greater than 10 units in $24 \mathrm{~h}$ or 4 units in $1 \mathrm{~h}$ [4]. Although difficult to manage, clinicians can readily recognize massive bleeding. However, consistent definitions in non-massive bleeding are elusive. Non-massive bleeding has clinical implication given resources and blood products required to manage these patients. To establish evidence-based interventions to reduce the resources used in non-massive bleeding, consistent nomenclature is required.

Treating bleeding in critically ill patients is a dynamic and complex process which is challenging to study, and extrapolating results from studies conducted in nonbleeding patients, or those who are less severely ill may not always be justified. Moreover, transfusion strategies during bleeding may involve multiple concurrent strategies for monitoring coagulopathy, transfusing blood products, and administering medications to support coagulation. Consequently, there is substantial worldwide variation in the treatment of critically ill patients with bleeding, and the availability of transfusion protocols in ICUs [5].

\section{Scope and objectives of this guideline}

Recognizing wide variation in transfusion practice, the European Society of Intensive Care Medicine (ESICM) created a taskforce (TF) to develop evidence-based recommendations for transfusion guidelines in the ICU and to identify knowledge gaps for future research priorities. The TF divided its recommendations into two sets of guideline recommendations. The first addressed transfusion in non-bleeding critically ill patients [6]. This manuscript includes guidelines for transfusion in critically ill patients with bleeding, including a wide variety of patient populations, not all of which are addressed in other guidelines.

The TF developed this guideline to assist critical care clinicians working in adult ICUs, with a scope including a broad set of patient populations cared for in the ICU, and transfusion-related interventions of relevance to bedside clinicians caring for bleeding patients, including use of blood products, transfusion ratios, point of care testing, and use of pharmacological agents to manage fibrinolysis (primarily tranexamic acid [TXA]). Blood pressure monitoring and targets, fluid resuscitation, vasopressor management, and bleeding source control, were considered to be beyond the scope of this guideline. Given the rapidity with which critically ill patients with bleeding can deteriorate, having a standardized approach to transfusion in these patients can be of great assistance to clinicians working in time-pressured circumstances.

\section{Take-home message}

In this clinical practice guideline, we highlight the current evidence for management of bleeding ICU patients and areas for further research

However, TF acknowledges that while this guideline can provide recommendations for transfusion practice in critically ill patients, specific patient characteristics and clinical circumstances may require the use of an individualized approach, integrating patient values and preferences, local resources, and patient judgement.

\section{Methods}

Taskforce membership

The TF included 15 clinicians with expertise in critical care medicine, anesthesiology, hematology, cardiac surgery, gastroenterology and transfusion medicine, along with methodologists experienced in guideline development using Grading of Recommendations, Assessment, Development, and Evaluation (GRADE) [7]. TF members were chosen based on their content and methodology expertise. The TF and methodologists were jointly involved in all aspects of the development of the guideline including development of PICO (population, intervention, comparison, and outcomes) questions, updating literature searches, assessing quality of evidence, formulation of recommendations, and manuscript writing. As the guideline did not have a patient representative on the panel, perspectives on patient values and preferences for transfusion and outcomes were obtained from a literature review.

\section{Conflict of interest}

At the beginning of the guideline process, and prior to submission of the manuscript, all TF members disclosed potential conflict of interest (COI). These included financial, intellectual, and personal COI. TF members were excused from voting on recommendations on any PICO questions where the TF chair considered significant $\mathrm{COI}$ to exist.

\section{Sponsorship}

The ESICM sponsored the development of this guideline and ESICM representatives were updated throughout the guideline process. There was no industry involvement in any aspect of the guideline.

\section{Question development and outcome prioritization}

The initial list of PICO questions was developed by the TF chairs (AV, MC). TF members were invited to submit additional PICO questions on topics related to blood product 
transfusions, transfusion protocols, point of care testing, and use of other medication in massively and non-massively bleeding critically ill patients. Following discussion of each PICO via teleconference, the TF voted anonymously on the questions in May 2019, using an online survey, rating the priority of each PICO on a scale of 1-10, with the highest rated PICOs being addressed in the TF guideline. The TF chose to address "massive" vs. "nonmassive" bleeding separately. We used the author definitions of massive (ex. use of $>10$ units of red blood cells $(\mathrm{RBC})$ in $24 \mathrm{~h}$ or $>6$ units in $6 \mathrm{~h}$ ) and non-massive bleeding. A list of potentially relevant outcomes for each PICO question was developed at a general TF meeting (ESICM Lives 2019, Berlin, Germany). Outcomes were prioritized according to standard methods used in GRADE, using an anonymous online voting system, with each outcome being rated from 1 to 9, as "critical" (rating 7-9), "important" (4-6), or "limited importance" (1-3), according to the relative importance of each outcome to patients[8]. Critical outcomes were mortality (all-cause or bleedingrelated), quality of life, functional recovery and stroke. Important outcomes included myocardial infarction, renal failure requiring renal replacement therapy (RRT), acute respiratory distress syndrome (ARDS), transfusion-related lung injury (TRALI), volume overload, venous thrombosis, length of stay (ICU and hospital), post-transfusion infections, and hemodynamic stability.

\section{Search strategy and study inclusion}

For each PICO question, a methodologist (SO) updated searches from published systematic reviews and developed new search strategies, with the input of other TF members (supplementary materials). We searched MEDLINE, EMBASE, and Cochrane databases for each PICO up to September 2019, along with trial databases (clinicaltrials. gov and ISRCTN) to identify in-progress trials, which were incorporated into the literature reviews as they became available. Search results were uploaded into Rayyan [9] for screening. Two reviewers from the TF screened the search results for relevant English-language systematic reviews (SRs), randomized controlled trials (RCTs), and observational studies. Any citation identified by either reviewer as potentially relevant underwent full text review, which were in turn also screened by two reviewers, with disagreements about inclusion at the full text resolved by discussion, with input from a third TF member.

\section{Data abstraction and risk of bias assessment}

Using a standardized, piloted data abstraction form, the methodology team conducted data abstraction for all included studies. To ensure consistency and prevent transcription errors, a second reviewer validated the data. With input from other TF members, the methodology team also conducted risk of bias assessments for each included study using the Cochrane Risk of Bias tool for RCTs [10], or the Newcastle-Ottawa risk of bias assessment tool [11].

\section{Data analysis and rating of evidence}

When there was sufficient evidence for data pooling, metaanalyses for each PICO question were conducted using RevMan v 5.3 [12]. For all outcomes, we compared fixed- and random-effects estimates, generally using fixed-effects models when the number of studies was very small (5 or fewer) or there were concerns that small-study effects may be impacting the pooled estimate; otherwise we used random-effects models [13]. For dichotomous variables, we reported relative risk (RR) and absolute risk difference (RD). For continuous variables mean difference (MD), or standardized mean difference (SMD), as appropriate, each with a corresponding 95\% confidence interval (95\% CI). Exploratory, post-hoc subgroup analyses were performed to explore potential sources of statistical heterogeneity (e.g. patient population, interventions, comparators, and outcomes reported). Following GRADE guidance, if unexplained heterogeneity was found, we rated down the certainty/quality of the evidence for that outcome. If heterogeneity was explainable using subgroup analysis, the panel considered this in formulating recommendations and implementation considerations. For questions in which insufficient quantitative data were available to conduct a meta-analysis, the evidence was summarized in narrative fashion.

\section{Evidence summaries and formulation of recommendations} The methodology team (SO, JCD) developed evidence summaries for each PICO question (supplementary materials), including information on study design, population, intervention, pooled estimates of effect for each outcome, and a rating of the overall quality of evidence. We rated the certainty of evidence for each outcome as "high," "moderate," "low," and "very low." In accordance with GRADE, the task force initially categorized the certainty of evidence for each outcome as high if it originated from RCTs and low if it originated from observational data. We subsequently rated down the quality of the evidence by one or two levels if results from individual studies were at serious or very serious risk of bias [14] there were serious inconsistencies (heterogeneity) in the results across studies [15] the evidence was indirect [16], the data were imprecise [17], or publication bias was thought to be likely. Evidence from observational data could be rated upwards if effect sizes were large, there was evidence of a dose-response gradient, or all plausible confounding would either reduce a demonstrated effect or suggest a spurious effect when results showed no effect. 
Evidence to decision (EtD) frameworks were completed by a subgroup of TF members for each PICO question to develop a draft recommendation considering the balance of desirable and undesirable effects, certainty of effects, resource considerations, feasibility, acceptability, and equity issues. While the TF planned to meet in March 2020 for final discussion and voting on the results, this meeting was cancelled in light of the coronavirus disease 2019 (COVID-19) pandemic. Instead, the TF used Panel Voice to vote on the strength and direction of the recommendation, after reviewing the EtD framework and draft recommendations created by each subgroup. A minimum of two rounds of voting were held to achieve consensus, if a consensus was not reached after two rounds a third round was held. We achieved approval on all recommendations after 2 rounds of voting. A priori, the task force chair decided that recommendations had to receive at least $80 \%$ of the vote of the panel to be approved [18].

Executive summary of recommendations: recognizing significant variation in transfusion practices to correct for anemia and/or coagulopathy in bleeding critical care patients, the ESICM assembled a task force to summarize the existing evidence regarding transfusion practices and transfusion avoidance strategies in bleeding, critically ill adults. The TF chose to address "massive" vs. "non-massive" bleeding separately. We used the author definitions of massive (ex. use of $>10$ units of RBC in 24 hours or $>6$ units in 6 hours) and non-massive bleeding. In addition, the task force aimed to develop clinical practice recommendations, identify knowledge gaps, and areas for future research.

\section{Transfusion support in massively bleeding, critically ill adults}

\section{Part 1: massively bleeding patients}

The following recommendations pertain to patients with massive bleeding.

\section{Transfusion ratios}

Recommendation
We suggest use of high-ratio transfusion strategies (at least one unit
plasma per two units of packed red blood cells) vs. low-ratio transfu-
sion strategies in critically ill patients with massive bleeding due to
trauma (Conditional recommendation, low certainty of evidence).
We make no recommendation regarding the use of fixed high-ratio
transfusion strategies in critically ill patients with non-traumatic mas-
sive bleeding (No recommendation, very low certainty evidence).

\section{Evidence summary}

We evaluated both randomized and non-randomized evidence regarding transfusion ratios in trauma [19].
The observational trauma evidence suggests high transfusion ratios ranging from 1:1 to 1:2 fresh frozen plasma (FFP): $\mathrm{RBC}$ result in a large mortality benefit early on (RR $0.51,95 \%$ CI $0.39-0.65$; RD - 12.6, 95\% CI - 15.7 to $9 \%$, very low certainty) and at 30 days (RR $0.63,95 \% \mathrm{CI}$ $0.54-0.73$; RD $-12.6,95 \% \mathrm{CI}-15.6$ to $-9.2 \%$, very low certainty), though these results may be confounded via survivorship bias, as in initial studies patients who lived long enough to receive thawed plasma may have been be less sick than patients who died before plasma was available. Reassuringly, in a subgroup analysis of studies excluding patients who died very early (usually within $1 \mathrm{~h}$, before plasma may be available), the mortality benefit was still evident (RR 0.67, 95\% CI 0.68-0.93).

Given concerns regarding residual confounding in the observational data, the panel relied primarily on evidence from the two available RCTs.[20, 21], in which high FFP: transfusion and high platelet ratios 1:1:2 compared to 1:1:1. The pooled results did not result in a mortality benefit at $24 \mathrm{~h}$ (RR $0.75,95 \%$ CI $0.52-1.08$; RD - 4.2\%, $95 \% \mathrm{CI}-8.1$ to $1.4 \%$, moderate certainty) and 30 days (RR 0.93, 95\% CI 0.72-1.2; RD - 1.7\%, 95\% CI - 7 to 5 , low certainty), though these results were limited by imprecision. Higher transfusion ratios may result in better clinical hemostasis, reducing probability of death by exsanguination (RR 0.7, 95\% CI 0.51-0.96, RD - 23.7\%, $95 \%$ CI -38.8 to -3.2 , low certainty) although certainty is limited by inconsistency between the two studies. There appeared to be no difference in rates of stroke, myocardial infarction (MI), ARDS/TRALI, congestive heart failure $(\mathrm{CHF})$, infections, and venous thrombo embolism (VTE) although these results were limited by serious or very serious imprecision and cannot rule out a meaningful effect. There is moderate certainty that high transfusion ratio results in a greater proportion of patients receiving plasma (RR 1.2, 95\% CI 1.01 to 1.43; mean difference 2 units, $95 \% \mathrm{CI} 0.99$ to 3.01) and platelets (RR 1.4, 95\% CI 1.07-1.83; MD 6 95\% CI 4.66-7.34), without a difference in RBCs transfused (MD 0 units, $95 \%$ CI -1.11 to 1.11 ).

In non-trauma patients, we identified several observational studies, 3 in mixed populations [22-24] 2 in cardiac and vascular surgery [23, 25], and 2 in postpartum hemorrhage $[26,27]$. The overall certainty of evidence was very low for all outcomes for these groups, with limitations due to study design and imprecision. High ratio transfusion may result in more plasma transfused (MD 4.15 units, 95\% CI 0.28 to 8.02), with no difference in platelets (MD 2.92, 95\% CI -2.52 to 8.36 ) or PRBCs (0.49, $95 \%$ CI -2.55 to 3.52$)$, though certainty of evidence is very low. 


\section{Justification}

Although the large reduction in mortality with the use of higher ratios seen in observational studies is more modest (and only seen for early death due to exsanguination) and less precise in the RCTs, it is reassuring that the direction and magnitude of the effects are similar, showing a reduction in early and late mortality with highration transfusion strategies. Additionally, the improved hemostasis demonstrated in the PROPPR trial [20] provides a sensible mechanism by which high-ratio transfusion could prevent deaths, this could be driven by the higher number of platelets received. Very few undesirable clinical effects were seen leading the panel to determine that even if of uncertain magnitude, the desirable effects likely outweigh the undesirable effects. It should be noted that few undesirable clinical effects were seen, the investigators did not seek to explore these at the initiation of the study. Due to the lack of certainty for many outcomes, along with the resource implications for increased use of plasma and platelets, the panel chose to make a conditional recommendation for fixed, high-ratio transfusion in trauma patients with massive bleeding.

The panel decided on the basis of the limited existing evidence that no recommendation for or against the use of fixed high-ratio transfusion could be made outside of the trauma setting, especially given potential differences in pathophysiology and coagulopathy compared to nontraumatic bleeding, and the resource implications of increased plasma and platelet transfusions.

\section{Implementation issues}

The PROPPR [20] and Nascimento [21] studies compared high RBC: plasma:platelets ratios 1:1:1 transfusion ratios to a low ratio of $2: 1: 1$, or transfusion guided by coagulation testing. If a fixed high-ratio transfusion approach is used, the 1:1:1 ratio is the most reasonable approach to initiate empiric transfusion when massive hemorrhage is suspected. Although the panel chose not to make a recommendation regarding fixed-dose transfusion ratios outside of the setting of trauma, many centers have developed massive transfusion protocols to cover all clinical scenarios, based upon extrapolation from the trauma literature. While the TF judged that the existing evidence does not support high-ratio transfusion outside of trauma, there may be important clinical impacts from the use of standardized massive transfusion protocols, beyond the effects of altered transfusion ratios alone, such as having a coordinated and efficient response to acute bleeding [28].

\section{Platelets}

\section{Recommendation}

We make no recommendation regarding the use of cryopreserved or cold-stored platelets in bleeding patients with massive or non-massive hemorrhage (No recommendation, very low certainty of evidence).

\section{Evidence summary}

There is little evidence regarding the use of cryopreserved or cold-stored platelets for the treatment of hemorrhage in comparison to conventionally stored (room temperature, $20-24{ }^{\circ} \mathrm{C}$ ), "standard" platelets. We identified two small studies, one comparing cryopreserved platelets to standard platelets and one comparing cold-stored platelets to standard platelets.

The first study was a single center non-randomized observational study of standard (fresh apheresis) platelets and cryopreserved platelets (frozen at $-80{ }^{\circ} \mathrm{C}$ and later reconstituted in thawed plasma) in a broad set of hemorrhaging patients [29]. Multiple clinical outcomes were evaluated, including 30-day survival, overall blood product use, TXA and fibrinogen concentrate use, and adverse events. There was no appreciable difference in 30-day mortality (RR 1.26, 95\% CI 0.41-3.88; RD 5\%, 95\% CI - 11.2 to 5.49 ; very low certainty) or other outcomes.

The second study was a single center two-stage pilot $\mathrm{RCT}$ of the use of cold-stored $\left(2-6^{\circ} \mathrm{C}\right)$ platelets adult cardiothoracic surgery patients; the first stage utilized platelets stored in the cold for up to 7 days, while the second stage utilized those stored in cold for 8-14 days [30]. The primary outcome reported was the difference in median blood loss (as measured by chest drain output): the difference in median blood loss between room temperature and cold-stored up to 7 days was - $216 \mathrm{ml}$ (95\% CI 465.7 to 33.68 , very low certainty); the difference between room temperature and cold-stored for 8-14 days was $986 \mathrm{~mL}$ (95\% CI -296.13 to 2268.1 , very low certainty). Secondary outcomes (total blood usage, adverse events, ICU length of stay, mortality) were comparable among those receiving cold-stored and standard platelets, but the number of events was very small in this pilot study.

\section{Justification}

Despite similarities in nomenclature, cryopreserved and cold-stored platelets are dissimilar blood products, and the rationale for their preparation and use equally dissimilar. Cryopreserved platelets are intended to have a substantially longer shelf-life than standard apheresis platelets (years versus days), thus reducing potential limitations in the platelet supply and providing products where and when standard platelets are not available. Cold-stored or cryo-stored platelets, on the other hand, 
have potentially longer shelf-lives than standard units and, based on in vitro and preliminary clinical studies, may be more hemostatically active than their room-temperature counterparts. The TF identified two published clinical studies on the use of these products compared to standard platelets, and despite the fact that each study did not demonstrate results unfavorable to cryopreserved or sold-stored platelets, both had sample sizes that were too small to provide anything beyond a very low degree of certainty in their results. Therefore, while both cryopreserved and cold-stored platelets are theoretically appealing, it was judged that there was insufficient evidence to make a recommendation for or against their use in the bleeding patients.

\section{Prothrombin complex concentrate and plasma}

Recommendation

We make no recommendation for the use of PCC versus plasma alone in massively bleeding patients due to very low certainty of evidence from observational studies only (No recommendation, very low certainty of evidence).

\section{Evidence summary}

For all patient populations, only observational studies were included in the analysis [31-35]. Thereby, risk of bias is high, most importantly related to a mismatch in disease severity. For cardiac surgery, none of the relevant patient outcomes differed between arms. There is a reduction in RBC transfusions in favour of the PCC arm, but chest tube output was not different. For trauma, pooling of data suggests a decrease in mortality, but this was found in a single study only. Of note, all trauma studies reported a decrease in transfusion requirements in the PCC arm, which is congruent with a mortality benefit. However, there were considerable differences in the comparator arms, hampering any recommendation. For liver transplant and TBI, there was insufficient data. Taken together, there is insufficient data on efficacy and safety of PCC in all categories of bleeding patients. With the lack of evidence and concern for safety, PCC use should be reserved for clinical trials.

\section{Justification}

There was no clear signal of harm, in particular no increase in thromboembolic events in the PCC arm; however, this is based on very low certainty of evidence. Thereby, we do not recommend against the use of PCC. However, it is not clear how robust the data were gathered, hampering the weighing of benefit and harm. Other concerns that preclude a recommendation to use PCC relate to cost-effectiveness and to a lack of knowledge on potential conflict of interest related to funding sources of the included studies.

\section{Research priorities}

The TF rated optimal management of massive bleeding as a clear priority. The very low level of evidence of benefit across all patient populations as well as the absence of harm of PCC, point towards a strong research priority assessing the efficacy and safety of the use of PCC in the treatment of bleeding.

\section{Fibrinogen}

\section{Recommendation}

We make no recommendation regarding the use of early empiric fibrinogen replacement in critically ill patients with massive hemor-

rhage due to trauma (No recommendation, low certainty evidence).

\section{Evidence summary}

In patients with massive bleeding due to trauma, it is unclear whether or not early, empiric fibrinogen administration is beneficial, compared to a strategy of fibrinogen replacement once hypofibrinogenemia is documented. The 5 RCTs [36-39] identified are small, with inconsistent and imprecise impact upon overall mortality (RR 1.02, 95\% CI $0.33-3.11$; RD $0.3 \%, 95 \%$ CI -10.3 to 32.6 , low certainty) and deaths due to hemorrhage (RR 0.77, 95\% CI $0.27-2.18$; RD $-2.3 \%$, 95\% CI -7.4 to 12 , low certainty). The impact upon other patient outcomes, including transfusion requirements are similarly unclear, without any clear signal for harm nor benefit.

\section{Justification}

While observational studies demonstrate a relation between hypofibrinogenemia and coagulopathy as well as with adverse outcome of bleeding due to trauma [40-42], thus providing a strong theoretical rationale for supplementation of fibrinogen during bleeding, clinical evidence for early fibrinogen supplementation remains unclear. The existing RCTs demonstrate that it is feasible to increase fibrinogen levels and FIBTEM values with fibrinogen concentrates, suggest that fibrinogen may reduce transfusion needs in patients with a low fibrinogen level, but the impact of an early/empiric fibrinogen replacement strategy compared to one guided by coagulation testing remains unclear. Similarly, the ideal, fibrinogen dose and target level are not clear. Observational studies in trauma suggest a relation with low levels and mortality; conversely a possible association between higher fibrinogen levels and mortality [42] as well as with thrombosis [43]. More evidence is need regarding empirical and lab-based supplementation before a recommendation for or against early fibrinogen can be made; at the 
present time, either approach is justifiable on theoretical grounds.

\section{Implementation issues}

If a fibrinogen-based strategy is chosen, studies in trauma suggest that this would confer the greatest benefit in those with low fibrinogen lab values; however, this threshold may be different in other populations; thus, if an early fibrinogen replacement strategy is used, it would ideally incorporate rapid laboratory testing to guide clinicians on when empiric fibrinogen should not be used.

\section{Point of care testing}

Recommendation
We suggest for either for viscoelastic or conventional coagulation
assays to guide transfusions in massively bleeding trauma critically ill
patients (Conditional recommendation, low quality of evidence).

For evidence summary and justifications, please see below section on point of care testing.

\section{Part 2: transfusion support in non-massively bleeding critically ill adults}

\section{RBC transfusion}

Recommendation

In patients with non-massive bleeding after vascular surgery, we suggest restrictive $(7.5-8 \mathrm{~g} / \mathrm{d} / \mathrm{L})$ red blood cell transfusion threshold

(Conditional recommendation, low certainty).

\section{Evidence summary}

A single RCT [44] of patients undergoing vascular surgery evaluated a restrictive $(8 \mathrm{~g} / \mathrm{dL})$ vs. liberal $(9.7 \mathrm{~g} /$ dL) transfusion strategy in patients with bleeding. Due to the small number of events in the study, the results were very imprecise for most outcomes, including mortality (RR 2, 95\% CI 0.19-20.86; RD 3.4, 95\% CI - 2.8 to 68.5 , low certainty) and myocardial infarction (RR 1, 95\% CI 0.15-6.63; MD 0, 95\% CI - 5.9-38.8, low certainty). A restrictive transfusion threshold appeared to result in lower number of transfusions (MD 2 units, 95\% CI 3.220.78 , high certainty) and proportion of patients receiving transfusions (RR 0.66, 95\% CI 0.51-0.86, high certainty), without a significant reduction in the risk of transfusion reactions ( $R R$ R $0.33,95 \%$ CI $0.01-7.86$, very low certainty).

\section{Justification}

The existing evidence does not demonstrate important clinical benefits or harms with restrictive vs liberal transfusions in vascular surgery patients, beyond reductions in red cell transfusion, with all estimates having low certainty because of the very small number of events, resulting in very serious imprecision. The absence of evidence for a treatment effect on clinically important outcomes, reduces the likelihood that patient values and preferences will have a role on decision-making. However, it is still expected that most patients would choose not to have a transfusion if it does not improve symptoms or other outcomes.

\section{Implementation issues}

The restrictive threshold suggested by the TF includes a slightly higher range than that recommended for most populations in part 1 of the guideline, including the recommendation for a restrictive transfusion threshold of 7.5-8 g/dL recommended for patients undergoing cardiac surgery, a population of similar age and with similar vascular comorbidities. This difference reflects the thresholds studied in the available clinical trials, but also reflects the significant cardiovascular comorbidities in this patient population, and clinical uncertainty given the limited direct evidence available to guide practice. As a result, there may remain some variability in how clinicians implement this restrictive strategy, based upon the volume of bleeding, ease of definitive hemorrhage management, presence of active cardiac disease, and patient symptoms.

\section{Recommendation \\ In patients with non-massive postpartum hemorrhage, we suggest restrictive transfusion, guided by presence of shock and symptoms potentially attributable to anemia (e.g. dyspnea, syncope, tachycardia angina, neurological symptoms) or hemoglobin $<6 \mathrm{~g} / \mathrm{dL}$, rather than at a liberal target hemoglobin of $9 \mathrm{~g} / \mathrm{dL}$ (Conditional recommendation, low certainty).}

\section{Evidence summary}

A single randomized controlled trial [45] of anemic postpartum patients with a hemoglobin $(\mathrm{Hb})$ of $49-79 \mathrm{~g} / \mathrm{L}$ found that that a restrictive red cell transfusion strategy guided by patient symptoms compared with liberal transfusion target $(\mathrm{Hb}>89 \mathrm{~g} / \mathrm{L})$ may result in no difference in terms of quality of life, measured by SF-36 questionnaire (MD 0.1, 95\% CI - 3.5 to 3.3, low certainty), incidence of venous thrombosis (RR 0.99, 95\% CI 0.14 -6.97, low certainty), post-transfusion sepsis or infection (RR 1.08, 95\% CI 0.62-1.87, low certainty), or transfusion reactions (RR 0.14, 95\% CI 0.01-2.72, very low certainty). There were moderate resource savings associated with reducing blood transfusion, including reduced mean number of transfusions (MD 2 units) and mean cost reduction of $€$ 249 in the restrictive threshold arm. 


\section{Justification}

Evidence related to quality of life, although of critical importance in this particular cohort of patients, had to be rated as low certainty due to the lack of blinding at the time of assessment of the SF-36 questionnaire. Imprecision related to the reporting of post-transfusion sepsis and hospital-associated venous thromboembolism resulted in a low level of certainty in the pooled effects, while the number of transfusion reactions was very small, resulting in a very low level of certainty for very serious imprecision. Given the lack of clear evidence that liberal transfusion improves outcomes, including quality of life, and the increased use of blood products required, the panel chose to issue a conditional recommendation for restrictive transfusion for symptomatic patients only [45] (e.g. dyspnea, syncope, tachycardia, angina, neurological symptoms), along with a lower asymptomatic limit of $6 \mathrm{~g} / \mathrm{dL} \mathrm{Hb}$ to ensure 'buffer' in the event of unrecognized ongoing hemorrhage.

\section{Implementation issues}

Evidence in this setting is limited to a single trial, creating some concerns around the acceptability of a restrictive threshold for RBC transfusion, in particular whether there is a lower limit. In patients with minor hemorrhage, no symptoms, the decision to transfusion can be discussed with the patient, as preferences may vary. The TF suggested a restrictive transfusion threshold which is consistent with guidance from other societies, including the Royal College of Obstetricians and Gynaecologists $[46,47]$ which adopt both clinical and hematological criteria to guide the decision to perform blood transfusion. In patients with severe shock, uncontrolled bleeding a higher threshold may be considered, anticipating ongoing blood loss.

Recommendation

In patients with non-massive gastrointestinal bleeding, we suggest restrictive $(7 \mathrm{~g} / \mathrm{dL})$ transfusion vs. liberal $(9 \mathrm{~g} / \mathrm{dL})$ red blood cell transfusion threshold (Conditional recommendation, moderate certainty).

\section{Evidence summary}

A total of four RCTs [48-51] were identified that examined the impact of a restrictive versus a liberal transfusion strategy. A restrictive transfusion strategy led to a reduction in mortality (RR $0.63,95 \%$ CI $0.43-0.93$ ), risk of rebleeding (RR 0.61, 95\% CI 0.46-0.81), and volume overload (RR 0.13, 95\% CI 0.03-0.54). There was also an improvement in quality of life measured using EQ5D (MD 0.07, 95\% CI 0.02-0.12) with a restrictive strategy. There was no effect with regards to stroke (RR 0.56, 0.29 to 1.09), myocardial infarction (RR 0.62 , 95\% CI $0.26-$ 1.47), post-transfusion sepsis (RR 0.95 , 95\% CI $0.81-$ 1.13). There may be moderate cost saving with reduced risk of bleeding because of reduced number of patients requiring transfusion. There are no formal studies evaluating a restrictive versus liberal transfusion strategy in patients with gastro intestinal bleeding (GIB); however, with decreased number of transfusion and better outcomes, a restrictive strategy may be a cost-effective strategy.

\section{Justification}

The certainty of evidence for rebleeding, hospital length of stay, mean number of transfusions and proportion of patients receiving transfusion and mortality, stroke, volume overload consisted of moderate certainty of evidence. In comparison, there was low certainty of evidence for quality of life, myocardial infarction, acute kidney injury and transfusion reactions. Evidence was rated down for imprecision due to the low event rate, target sample size not met, and wide confidence interval. Overall, gastrointestinal (GI) bleeding patients, the panel had moderate certainty that a restrictive transfusion strategy is safe, and possibly results in improved outcomes, with fewer resources.

\section{Implementation issues}

There are no significant implementation considerations as the studies included those with gastrointestinal and portal hypertensive bleeding.

\section{Platelets}

\section{Recommendation}

We make no recommendation for the use of a restrictive vs a liberal platelet transfusion threshold in non-massively bleeding patients with thrombocytopenia (No recommendation, very low certainty evidence).

\section{Evidence summary}

We identified only one retrospective cohort study examining platelet transfusion in thrombocytopenic patients who had intracranial hemorrhage ( $\mathrm{ICH})[52]$ and had a platelet transfusion. The study had two cohorts (1) participants with $\mathrm{ICH}$ with reduced platelet activity based on the aspirin response test who received platelets (2) participants with $\mathrm{ICH}$ who received platelets. Each cohort was compared to aspirin responders and participants with $\mathrm{ICH}$ who did not receive platelets; outcomes examined included hematoma volume and expansion. There was no effect in hematoma size (RR 0.71, 95\% CI 0.34-1.47) or expansion (RR 1.44, 95\% CI 0.92-2.24, very low certainty) [52]. 


\section{Justification}

The evidence is of very low certainty due to the absence of studies evaluating platelet transfusion thresholds in bleeding patients with thrombocytopenia. The clinical effects and resource implications of higher vs lower platelet transfusion thresholds in bleeding patients are unclear. As a result, the TF did not make a specific recommendation of transfusion thresholds for patients with non-massive bleeding.

\section{Implementation issues}

We make no recommendation for the use of a restrictive or a liberal platelet transfusion threshold in bleeding patients with thrombocytopenia, and as such either strategy could be considered based on individual patient characteristics. However, recommendations made in Part 1 of the guidelines set lower limits after which prophylactic platelet transfusion should be considered, irrespective of bleeding.

\section{Recommendation \\ We suggest using a restrictive platelet transfusion strategy (no transfu- sion) in patients with intracranial hemorrhage (spontaneous or traumatic intracerebral hemorrhage) who are on antiplatelet therapy (Conditional recommendation, moderate certainty evidence). \\ We make no recommendation for the use of a restrictive (no transfu- sion) vs liberal platelet transfusion strategy in critically ill patients with non-massive bleeding who are on antiplatelet therapy (No recom- mendation, very low certainty of evidence).}

\section{Evidence summary}

Two randomized trials have investigated platelet transfusion in patients on antiplatelet therapy with spontaneous intracranial hemorrhage ( $\mathrm{ICH})$, neither finding a benefit with platelet transfusion [52, 53].The PATCH trial [53] included 190 non-thrombocytopenic patients with ICH, with a Glasgow Coma Scale (GCS) score $>8$ who had received antiplatelet medications. The composite endpoint of death or dependence at 3 months was higher in patients receiving platelet transfusion than in those who did not (RR 2.05, 95\% CI 1.18-3.56, $p=0.014$ ), there was no significant difference in the individual outcomes including mortality. The second RCT compared postsurgical hemorrhage in patients with antiplatelet therapy and who underwent craniotomy for acute $\mathrm{ICH}$, finding liberal platelet transfusion (in comparison to restrictive platelet transfusion) was not associated with a difference in post-surgical bleeding volume. Overall, the pooled evidence from these two RCTs, suggests there is no difference in mortality at 3 months (RR $0.71,95 \%$ CI $0.44-1.14$ ) overall mortality (RR $0.84,95 \%$ CI $0.58-1.22$ ), disability at 3 months or by the ADL, or bleeding volume.
We identified only one retrospective single center study comparing platelet transfusion strategies in patients on antiplatelet agents with non-massive bleeding for $\mathrm{ICH}$ [54]. This was a case control study in patients with GI bleeding, patients who did not receive platelet transfusion had a lower mortality (RR $0.21,95 \%$ CI $0.06-0.73$ ), less cardiac event (RR $0.55,95 \%$ CI $0.31-0.98$ ) and lower recurrent bleeding (RR 0.71, 95\% CI 0.56-0.9).

\section{Justification}

Antiplatelet therapy effect lasts for up to 10 days leading to an increase in hemorrhage occurrence and severity. Observational studies have reported a poorer outcome in patients with ICH receiving antiplatelet therapy. Transfusion of platelets in this setting might offset antiplatelet therapy effect, improve hemostasis and outcome. However, the two existing RCTs $[52,53]$ reported similar, or possibly worse outcomes in patients receiving platelet transfusions. Given the lack of evidence for any desirable effects, the possible adverse effects related to platelet transfusion, the cost of transfusion and the fact that platelets are a limited resource, the panel made a conditional recommendation to not administer platelets in patients on antiplatelet agents with $\mathrm{ICH}$.

The PATCH Trial [53] did included patients with $\mathrm{ICH}$ who have a GCS $>8$ which may limit the generalizability to ICU patients. There is even less evidence to guide platelet transfusion decisions in critically ill patients with non-massive bleeding other than $\mathrm{ICH}$ and on antiplatelet agents. While patients on antiplatelet therapy are at higher risk of GI bleeding and higher risk of severe bleeding and recurrent bleeding. However, cease of antiplatelet therapy or platelet transfusion might expose patients to major cardiac events including myocardial infarction. The benefit of one or the other platelet transfusion strategy might be impacted by the source of bleeding (ulcerous, variceal upper GI bleeding, colonic). Given the substantial uncertainties, we did not make a recommendation for or against platelet transfusion for critically ill patients on antiplatelet agents with bleeding other than $\mathrm{ICH}$.

\section{Implementation issues}

Given the lack of evidence, decisions about transfusing platelets in patients on antiplatelet agents need to be based upon individual considerations, including the severity and location of bleeding, consideration of risks of transfusion, and availability of blood products. Enthusiasm for platelet transfusion should be tempered given the lack of benefit in $\mathrm{ICH}$, in which even small difference in hemorrhage volumes would be expected to have an impact upon patient outcome; the benefit in other populations is likely to be even less certain. 


\section{Fibrinogen}

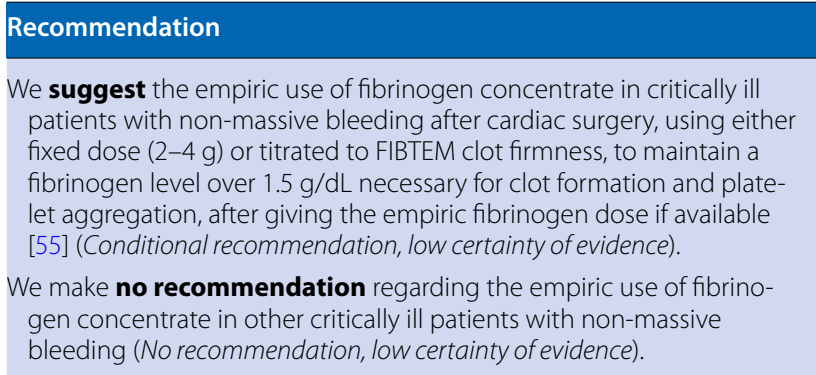

\section{Evidence summary}

We identified six RCTs evaluating the use of fibrinogen in patients with non-massive bleeding after cardiac surgery one comparing fibrinogen to FFP in major vascular surgery, and one comparing fibrinogen concentrate plus FFP to FFP alone in a mixed surgical population [56-62]. In cardiac surgery, the point estimate for mortality favours the use of fibrinogen, however, the number of events is small, resulting in very serious imprecision (RR 0.44, 95\% CI 0.17-1.19; RD - 2.9\% 95\% CI - 4.3 to 1 , low certainty). Fibrinogen likely results in a reduction in blood loss (MD - $88 \mathrm{~mL}, 95 \% \mathrm{CI}-149 \mathrm{~mL}$ to $26 \mathrm{~mL}$, moderate certainty) and may reduce the need for RBC transfusion (RR 0.62, 95\% CI 0.46-0.84; RD - 18\%, 95\% CI - 25.7 to $7.6 \%$, low certainty), plasma transfusion (RR $0.4495 \%$ CI $0.22-0.90$; RD $-10 \%, 95 \%$ CI -13.9 to $-1.8 \%$, low certainty), and platelet transfusion (RR $0.5,95 \%$ CI 0.29 0.86 ; RD $-10.5,95 \%$ CI -15.0 to $-3 \%$, low certainty) without impact upon other outcomes, including stroke, MI, AKI, venous thrombosis, infections, and length of stay. In the two small non-cardiac surgery studies, the number of events was small, and overall certainty of evidence was low due to very serious imprecision $[58,63]$.

\section{Justification}

The use of fibrinogen in patients with bleeding after cardiac surgery results in reductions in blood loss and use of blood products which are cost-effective; however, impact upon other patient-important outcomes, including mortality, is unclear. The TF determined there was insufficient evidence to provide guidance regarding the use of empiric fibrinogen concentrate in non-massive bleeding outside of the context of cardiac surgery.

\section{Implementation issues}

Fibrinogen is vital for the clot formation and platelet aggregation; the dose of fibrinogen varied between studies, ranging between 1 and $4 \mathrm{~g}$, and used varied targets, [56] FIBTEM clot firmness [58-61], or fixed-dose [57, 62, 63]. These studies used clinical bleeding as the trigger to initiate administration of fibrinogen concentrate rather than coagulation testing or FIBTEM. Once coagulation test results are available, they can be used alongside clinical assessment of bleeding to guide decisions about further fibrinogen administration. While ideal fibrinogen targets are unclear, it would be reasonable to maintain a fibrinogen level over $1.5 \mathrm{~g} / \mathrm{dL}$ necessary for clot formation and platelet aggregation, after giving the empiric fibrinogen dose [55].

Fibrinogen concentrate may not be available in all centers, in which case cryoprecipitate may be a reasonable alternative. While the recent FIBRES trial suggests that outcomes between fibrinogen concentrate and cryoprecipitate are similar in patients with cardiac-surgeryrelated bleeding-related to hypofibrinogenemia [64], rapid administration of fibrinogen administration in bleeding patients may be more easily achieved, as storage and reconstitution of the product (concentrate) is likely easier from a logistical standpoint compared to cryoprecipitate.

\section{Plasma}

\section{Recommendation}

We make no recommendation for a restrictive plasma versus a liberal plasma transfusion strategy for non-massively bleeding patients with or without coagulopathy (No recommendation, low certainty evidence).

\section{Evidence summary}

The panel sought evidence comparing liberal/empiric use of plasma to restrictive plasma transfusion, or no transfusion, in non-massively bleeding platelets. One RCT [36] was identified that evaluated the use of plasma in 90 blunt trauma (injury severity score $>16$ ) patients who received RBCs transfusion and had a fibrinogen level $<5.88 \mathrm{~g} / \mathrm{L}$ [36]. Patients were randomized to receive: 1) fibrinogen, 2) FFP (2 units), or 3) RBC transfusion alone. This study included non-massively bleeding patients, with a mean RBC transfusion requirement of $2 \pm 1.1$ (fibrinogen group), $2.7 \pm 0.7$ (FFP group) and $2.9 \pm 0.9$ (control group). There was no difference in mortality (RR 1, 95\% CI 0.51-1.94), multiorgan failure (RR 0.88 , 95\% CI 0.362.11) or length of stay (MD 4.4., 95\% CI 0.4-8.4) between restrictive and liberal plasma transfusion group (RR 1, 95\% CI 0.51-1.94). More sepsis (RR 0.25, 95\% CI 0.090.66 ) occurred in the liberal transfusion group. Considering the study groups, it is unclear whether plasma is due to fibrinogen effect and not plasma alone. More evidence is needed for the use of plasma infusions in non-massively bleeding patients. The basic science literature is emerging with a potential new resuscitation target of restoration of endothelial glycocalyx (EG) [65], in rat models of hemorrhagic [65] and septic shock improved survival 
with FFP compared resuscitation with crystalloids [66] with restoration of EG.

\begin{abstract}
Justification
The use of a liberal plasma transfusion strategy incorporating 2 empiric units of FFP in non-massively bleeding trauma patients did not demonstrate any benefit but did raise the possibility of harm (e.g. sepsis). However, this data is from one small RCT [36] and is of low certainty, limited by imprecision and risk of bias. The panel thus made no recommendation for plasma transfusion in patients without massive bleeding, or coagulopathy.
\end{abstract}

\section{Point of care vs. conventional coagulation testing}

\section{Recommendation \\ We suggest either viscoelastic testing or conventional coagulation testing to guide transfusions in massive and non-massively bleed ing cirrhotic patients, liver transplant patients or critically ill trauma patients (Conditional recommendation, low certainty evidence).}

\section{Evidence summary}

In massively bleeding cirrhotic patients, based on two RCTs $[67,68]$, there was uncertainty as to the effects of the implementation of viscoelastic on mortality (RR 0.82 , 95\% CI 0.59-1.13, low certainty), rebleeding (RR 0.71, 95\% CI $0.47-1.07$, very low certainty), transfusion associated cardiac overload (RR 0.48, 95\% CI 0.18-1.3, low certainty) and red cell transfusion (RR 1.06, 95\% CI 0.671.68 , low certainty). In these trials, there was evidence that the use of viscoelastic testing may reduce transfusion associated lung injury (RR 0.25 , 95\% CI $0.11-0.56$, low certainty), acute respiratory distress syndrome (RR 0.11 , 95\% CI 0.01-0.81, low certainty), platelet transfusion (RR 0.14, 95\% CI 0.05-0.43, low certainty) and fresh frozen plasma transfusion (RR $0.29,95 \%$ CI $0.11-0.77$, low certainty).

In massively bleeding liver transplant patients, based on the evidence pooled from a Cochrane Systematic review [69] and an observational study [70], there was uncertainty as to the effects of viscoelastic on mortality (RR 0.67, 95\% CI 0.13-3.4, low certainty), red cell transfusion (MD - 12.22, 95\% CI -71.08 to 46.64, very low certainty) and platelet transfusion (MD $-2.8,-14.92$ to 9.32, very low certainty). There was, however, evidence that elastic may result in less blood loss (MD -1.13, 95\% $\mathrm{CI}-1.85$ to -0.41 , very low certainty) and FFP Transfusion (MD - 8.7, 95\% CI - 16.3 to - 1.1, very low certainty) in massively bleeding liver transplant patients.

In massively bleeding critically ill trauma patients, in a randomised trial [71], the use of viscoelastic testing did not result in a significant mortality reduction (RR 0.54, 95\% CI 0.29-1.02, very low certainty).

\section{Justification}

Even though the positive effects of viscoelastic testing on a limited number of outcomes such as TRALI and ARDS might be moderate (in particular in the cirrhotic population), the limited number of studies, the substantial heterogeneity, the wide confidence intervals, and the imprecision in the estimates, determine the overall low confidence in the certainty of these results. These observations are applicable to all subgroups but are especially true in the case of trauma patients.

Recommendation
We suggest either viscoelastic testing or conventional coagulation
testing to guide transfusions in bleeding cardiac surgery patients
(Conditional recommendation, very low certainty of evidence).
We suggest using either viscoelastic testing or conventional coagula-
tion testing to guide transfusion in extra corporeal membrane
oxygenation (ECMO) patients with non-massive bleeding (Conditional
recommendation, very low certainty evidence).

\section{Evidence summary}

In non-massively bleeding cardiac surgery patients, based on two recent systematic reviews [72, 73], there is uncertainty as to the effects of viscoelastic on mortality (RR 0.6, 95\% CI 0.34-1.07, low certainty), and hospital length of stay (RR 0.86, 95\% CI 0.76-0.98, very low certainty). There was evidence of reductions in the risk of red cell transfusion (RR 0.86 , 95\% CI 0.76-0.98, low certainty), platelet transfusion (RR 0.68, 95\% CI 0.46-0.99, very low certainty), and fresh frozen plasma transfusion (RR 0.46 , 95\% CI $0.37-0.57$, very low certainty). Viscoelastic also resulted in reductions in 12-h postoperative bleeding (MD - $128.18 \mathrm{mls}$, 95\% CI -172.38 to -83.97 , very low certainty), in 24 -h postoperative bleeding (MD $-175.25 \mathrm{mls}, 95 \% \mathrm{CI}-305.19$ to 45.32 , low certainty), and ICU length of stay (MD $-4.08 \mathrm{~h}$, $95 \% \mathrm{CI}-6.33$ to -1.82 , very low certainty), although the clinical importance of these effects is unclear.

Based on the pilot randomized controlled trial by [74] the implementation of viscoelastic in managing nonmassively bleeding ECMO patients may not result in any difference in mortality (RR $0.86,95 \%$ CI $0.13-3.4$, low certainty), rebleeding (RR $0.43,95 \%$ CI $0.12-1.51$, very low certainty), or thrombotic complications (RR 0.2, 95\% CI 0.03-1.39, very low certainty).

\section{Justification}

There is uncertainty as to the effects of viscoelastic in non-massively bleeding cardiac surgery patients on clinically important outcomes. Most treatment effects were observed in outcomes that are particularly susceptible to performance bias, are of limited importance to patients, and demonstrated high heterogeneity. Moreover, most 
studies included in the systematic review $[72,73]$, were at unclear or high risk of bias. Two studies [75, 76], assessed the resource requirements and cost-effectiveness of this technology in the cardiac surgery population suggesting small cost savings over usual care, but substantial uncertainty remains. The single RCT [74] in patients undergoing ECMO provides only very low certainty evidence for the differences between viscoelastic testing and conventional coagulation testing.

\section{Implementation issues}

Despite the very low certainty provided by the available evidence, many centers have adopted the use of viscoelastic testing to guide transfusions, due to perceived efficiency, specificity, and rapidity of testing. However, for centers without viscoelastic testing, resource considerations and staff education needs, would likely play a role in deciding whether it should be adopted, in light of the limited evidence available regarding its impact upon patient outcomes and blood product use.

\section{Part 3. Tranexamic acid (TXA) in bleeding critically ill adults}

\section{TXA in patients with traumatic intracranial hemorrhage}

\section{Recommendation}

We recommend the use of early ( $<3 \mathrm{~h}$ from trauma) TXA in critically ill patients with bleeding or suspected bleeding due to trauma (Strong recommendation, high certainty).

\section{Evidence summary}

The landmark multi-centre CRASH-2 RCT demonstrated that administration of TXA results in a reduction of death (RR 0.91, 95\% CI 0.85-0.97; RD - 1.4\%, 95\% CI - 2.4 to -0.5 , high certainty), with no difference in venous thrombosis, stroke, myocardial infarction or need for surgical intervention [77]. The risk of seizures was not reported, though reassuringly no increase in seizures was noted in the CRASH-3 study, which evaluated the use of TXA in trauma patients with isolated traumatic brain injury [78].

\section{Justification}

Compared to placebo, TXA results in small but clinically meaningful reductions in bleeding death and overall mortality, with trivial undesirable effects. TXA is inexpensive, likely cost-effective, [79] acceptable, and feasible to implement in most settings.

\section{Implementation issues}

The dose of TXA given in CRASH-2 was a loading dose of $1 \mathrm{~g}$ IV over $10 \mathrm{~min}$, followed by $1 \mathrm{~g}$ IV over $8 \mathrm{~h}$. While some centers may use point of care testing (e.g. TEG/
ROTEM) to guide management of bleeding patients, the task force recommends early empiric use of the loading dose of TXA prior to such testing as point of care measurements have varying sensitivity for identifying hyperfibrinolysis [80] and earlier administration of TXA may be more effective at reducing mortality [81]. However, to date there is limited evidence to guide the use of very early, prehospital administration of TXA [82].

\section{Recommendation}

We suggest the use of TXA in critically ill patients with acute traumatic brain injury and bleeding due to trauma (Conditional recommendation, moderate certainty).

\section{Evidence summary}

A recent systematic review identified 9 RCTs which reported all-cause mortality, including unpublished data from CRASH-3, reporting that TXA does not reduce allcause mortality (RR 0.95, 95\% CI 0.88-1.02; RD - 1\%; $95 \% \mathrm{CI}-2.5$ to $0.4 \%$, moderate certainty) or disability as assessed with the disability rating scale (MD - 0.18, 95\% $\mathrm{CI}-0.43$ to 0.08 , moderate certainty [83]. Data from the largest trial, CRASH-3, suggests that TXA may reduce head-injury associated death when excluding patients with severe traumatic brain injury (TBI) whom are unlikely to survive with or without treatment (Glasgow Coma Score of 3 or bilateral unreactive pupils at baseline) (RR $0.89,95 \%$ CI 0.8 to 1 ; RD $-1.595 \%$ CI -2.8 to $0.4 \%)$. There appears to beno effect on risk of stroke, MI, venous thromboembolism, sepsis, surgical intervention, or seizure.

\section{Justification}

The use of TXA may not result in a reduction in mortality or disability in all patients, but there may be a reduction in head-injury-related mortality in patients who have mild to moderate TBI, as well as a reduction of progression of intracranial hemorrhage. Although the clinical relevance of these findings is unclear, most patients would likely accept TXA, given the demonstrated safety profile of TXA in this population, the possibility of concomitant non-head injuries for which TXA is indicated as per the previous recommendation, and the low cost and acceptability and feasibility of the intervention. Given the lack of certainty around patient-important effects, the panel chose to make a conditional recommendation for the use of TXA in this population.

\section{Implementation issues}

All studies used similar dosing to CRASH-2, with $1 \mathrm{~g}$ IV TXA loading dose followed by an infusion of $1 \mathrm{~g}$ IV 
maintenance infusion over a longer period of time. Some patients with TBI have other associated traumatic injuries; this recommendation supports the use of TXA in trauma with or without TBI, while the severity and nature of injuries is being assessed. As in the general trauma population, there is a suggestion that if TXA is given, it is most likely to be effective when given early, within $3 \mathrm{~h}$ although the prehospital may not be more effective [78, 84]. While some centers may use viscoelastic testing to guide interventions, early empiric use of TXA may still be beneficial, as point of care results may not be sensitive for hyperfibrinolysis [80].

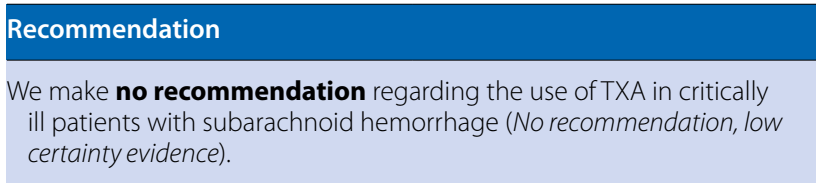

\section{Evidence summary}

A number of trials have evaluated anti-fibrinolytic therapies in patients with aneurysmal subarachnoid hemorrhage (SAH), 10 of which evaluated IV TXA [85-94]. These studies demonstrated no change in mortality (RR 1.01 , $95 \%$ CI $0.88-1.16$; RD $-0.3 \%$, $95 \%$ CI -3.2 to $4.2 \%$, moderate certainty) or poor functional outcome (RR 1.05, 95\% CI $0.95-1.15$; RD $-0.4 \%, 95 \%$ CI -1.9 to 5.8 , low certainty), but a reduced risk of rebleeding (RR 0.6, 95\% CI 0.44-0.8; RD - 7.8\%, 95\% CI - 11 to -3.9 , moderate certainty), offset by an increased risk of stroke (RR $1.29,95 \%$ CI 1.01 to 1.67 ; RD $6.1 \%, 0.2 \%$ to $14.1 \%$, low certainty). Only the recent ULTRA trial reported rates of venous thrombosis, which were rare but similar between groups [90]. Most trials were several decades old, with only the three most recent trials evaluated TXA within clinical context with the use of calcium channel blockers and endovascular coiling of aneurysms, though results appear generally consistent between older and newer trials $[87,90,91]$.

\section{Justification}

The panel did not make a recommendation regarding the use of TXA in SAH. The effects of TXA appear mixed, with a decreased risk of rebleeding, and a similar magnitude of increased stroke (both of which are themselves of uncertain clinical relevance in the context of these older studies in which diagnostic procedures may vary). Overall, there appears to be little impact upon mortality and the risk of poor functional outcome, although the evidence is insufficiently precise to rule out a clinically meaningful effect. The panel judged the available evidence as insufficient to make a recommendation, as the values and preferences of patients and clinicians regarding the risk of rebleeding vs. stroke may vary, such as when securement of aneurysm may be delayed.

\section{Implementation issues}

Given the uncertainty of the evidence and variations in local practice, decisions around the use of TXA in the population need be based upon individual factors, such as clinician concerns around risk of stroke vs. rebleeding, and time until definitive securement of aneurysm. Widespread use of TXA in this setting should await further evidence.

\section{TXA in patients with non-traumatic intracranial hemorrhage.}

\section{Recommendation}

We make no recommendation regarding the use of TXA in critically ill patients non-traumatic intracranial hemorrhage (No recommendation, moderate certainty).

\section{Evidence summary}

Three RCTs have evaluated IV TXA in non-traumatic $\mathrm{ICH}$, the majority of data from the large $\mathrm{TICH}-2$ trial which evaluated IV TXA in the acute phase of patients with ICH [95-97]. These studies demonstrate no change in mortality (RR 1.02, 95\% CI 0.88-1.19; RD 0.4\%, 95\% CI -2.5 to 4 , moderate certainty), poor functional outcome (RR 0.98, 95\% CI 0.93-1.04; RD - 1.4\%, 95\% CI - 4.9 to 2.8 ; moderate certainty). Other outcomes, including stroke, myocardial infarction, venous thromboembolism, seizure, and length of stay were also similar, although certainty was only moderate for all outcomes, limited my imprecision.

\section{Justification}

While the quality of evidence for critical outcomes was moderate, the point effect and confidence intervals for TXA did not indicate either benefit or harm in patients with $\mathrm{ICH}$. There is thus moderate evidence of no effect, but the use or non-use of TXA in this setting would be reasonable pending further evidence. The panel thus chose to make no recommendation for or against the use of TXA compared to no TXA in this setting.

\section{Implementation issues}

Further evidence is required before changes in practice regarding TXA use should be considered. Decisions around the use of TXA should recognize that the effects of TXA in this population remain uncertain. 
Table 1 Summary of recommendations

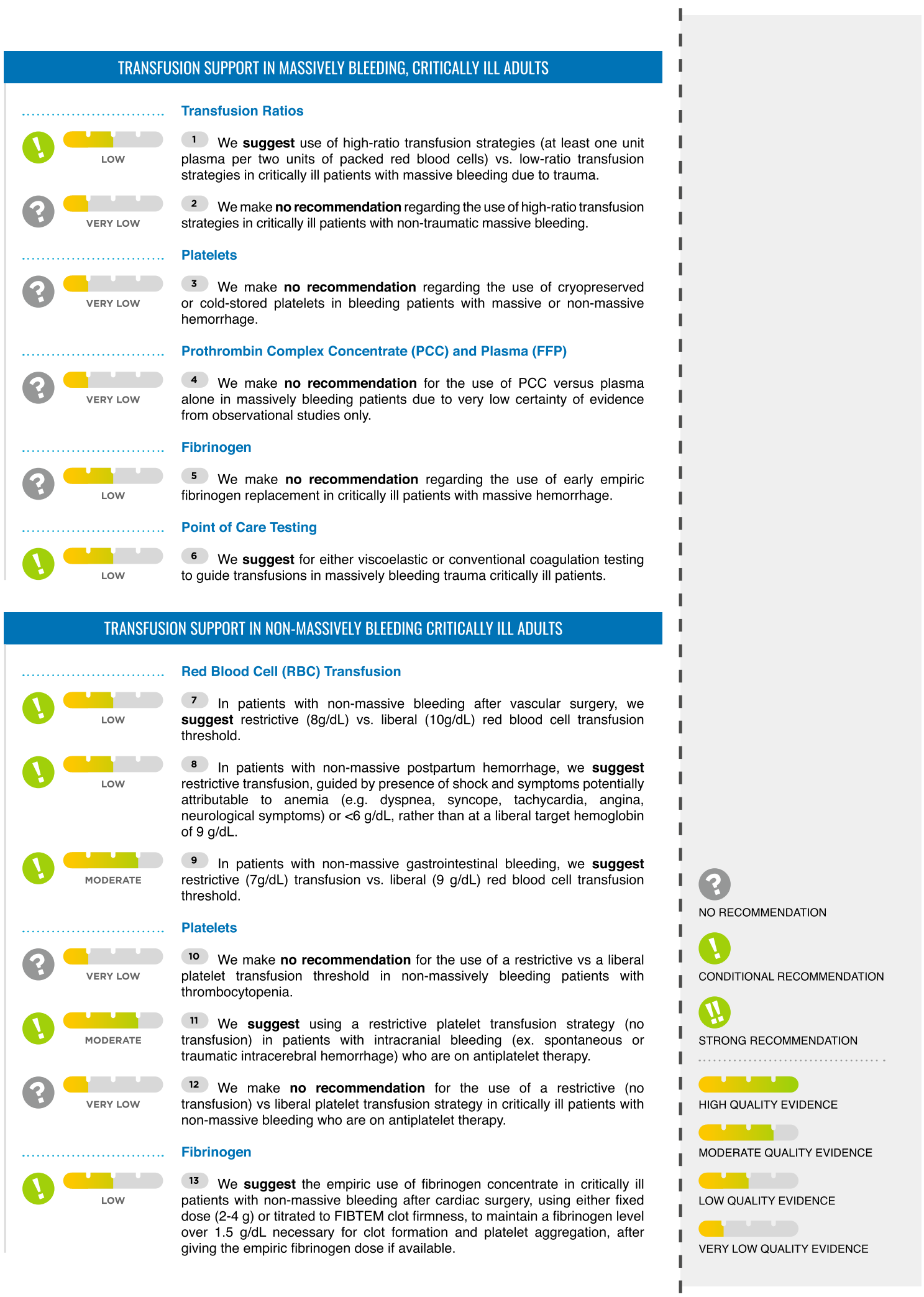


Table 1 (continued)

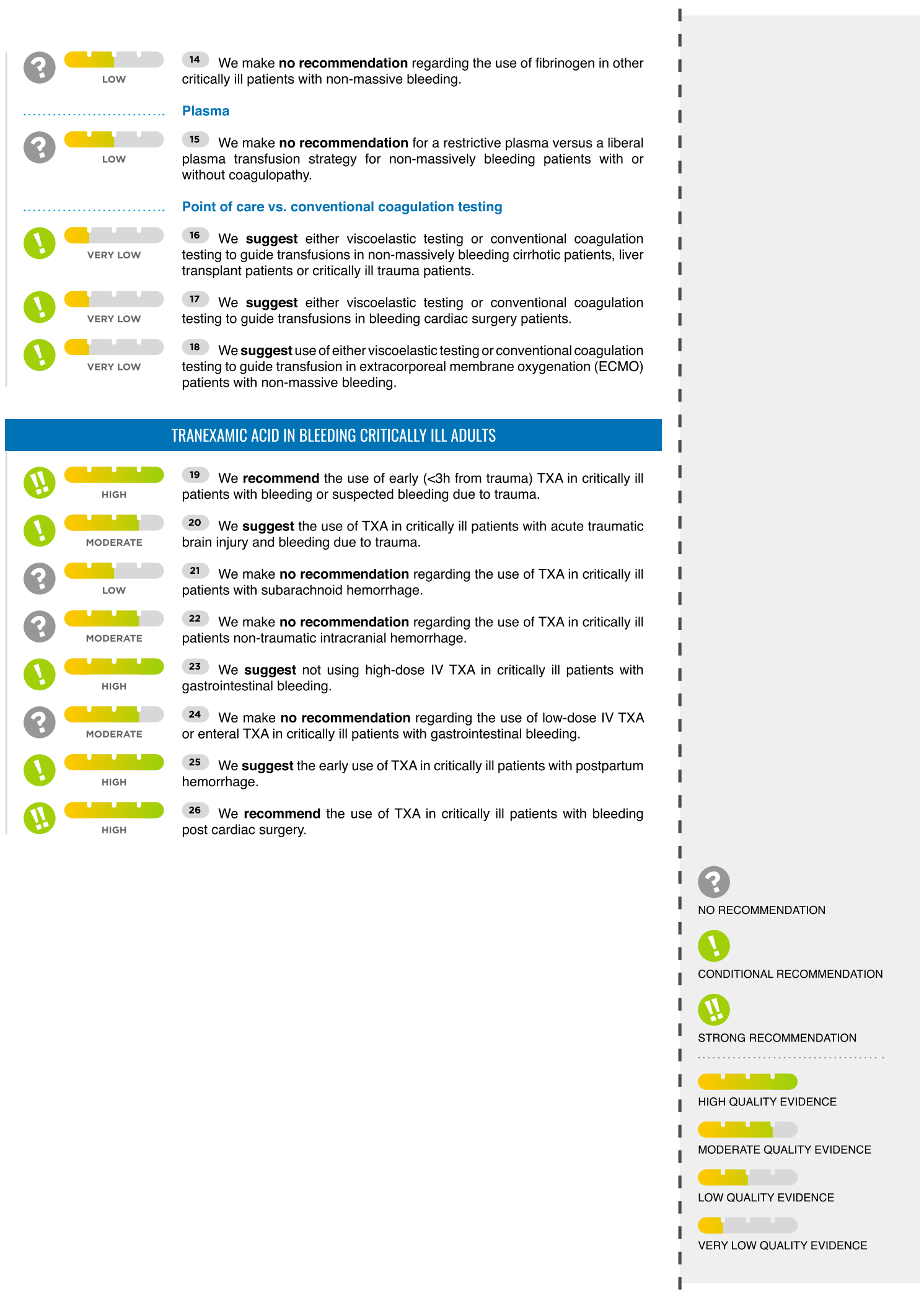

\footnotetext{
a Please see BOX 1 for interpretation of GRADE recommendations
} 
Table 2 Research priorities

\section{Section}

Transfusion ratios in massive bleeding

Cold-stored platelets

Prothrombin complex concentrate in massive bleeding

\begin{abstract}
Early fibrinogen replacement in massive bleeding
\end{abstract}
Thromboelastography vs conventional coagulation testing in massive bleeding

Red blood cell transfusion

Restrictive vs. liberal platelet transfusion in non-massive bleeding

Restrictive vs liberal platelets in patients on antiplatelet medications

Fibrinogen in non-massive bleeding

Plasma in non-massive bleeding

\section{Research priorities}

More high-quality, randomized data of massive transfusion protocols including high-ratio transfusion vs. low-ratio transfusion are required in trauma and non-trauma patients with massive bleeding

More RCT data on impacts of massive transfusion protocols guided by empiric transfusion ratios vs. guided by point of care testing

RCTs involving conventional and cold-stored platelets are needed in patient populations where rapid control of hemorrhage is vital, such as trauma-associated or obstetric hemorrhage. Key outcomes include clinical and blood product use, effects on measured hemostatic parameters, and patient-important outcomes

RCT data demonstrating the effects of prothrombin complex concentrate ( \pm fibrinogen concentrate) vs. conventional massive transfusion protocols are needed in both trauma and non-trauma populations with massive bleeding

Large-scale trials, including clear fibrinogen testing strategies, targets, products (cryoprecipitate vs concentrate), and populations are needed to guide decisions on the role of fibrinogen early in resuscitation

Trials comparing the use of thromboelastography to conventional coagulation testing protocols are needed to demonstrate the effects and economic impacts of implementing thromboelastography across a variety of patient populations with massive bleeding; these should incorporate transfusion protocols (eg. ratios, alternative blood products)

More research is needed on transfusions in patients undergoing vascular surgery, and other surgical populations at risk for significant bleeding and with cardiovascular comorbidities

More research is needed on quiding transfusions in low-risk patients with bleeding, such as healthy postpartum women, and surgical patients with few comorbidities

More studies are needed to examine the difference in the transfusion practice of a restrictive versus a liberal platelet transfusion practice in terms of outcomes, effects, patient values and preferences, as well as resources required to implement such strategies

Further research is required to define the platelet transfusion strategy with the restrictive strategy being no platelet transfusion in other subgroups of patients with non-major bleeding patients

This is an important research question as gastrointestinal bleeding is common and patients with cardiovascular diseases requiring antiplatelet therapy are increasing

Research is needed on which which triggers should be used for "early" or "empiric" fibrinogen administration in patients with bleeding, and specific targets for replacement (fixed dose vs. use of viscoelastic testing)

Future research should focus on 1) targeted personalized trial of using any point of care testing to assess presence and type of coagulopathy and determine transfusion requirements compared to transfusing patients based on clinical presentation; 2) restrictive versus liberal plasma transfusion strategies in non-massively bleeding critically ill patients with a coagulopathy and 3 ) exploring the correction of coagulopathy versus non-correction of coagulopathy in non-massively bleeding critically ill patients

RCTs comparing transfusion strategies guided by point of care testing vs. conventional coagulation testing, with and without fixed ratio blood product transfusions are needed to determine whether thomboelastography improves patient outcomes and impacts blood product use in critically ill patients

TXA in trauma and traumatic brain injury

More research is required to identify subgroups most likely to benefit from the use of TXA and the role of individualized patient use guided by thromboelastometry and conventional coagulation tests

TXA in subarachnoid hemorrhage
More research is needed on the role of TXA in specific patient populations, eg. those with delayed or challenging aneurysm securement 
Table 2 (continued)

$\begin{array}{lr}\text { Section } & \begin{array}{l}\text { Research priorities } \\ \text { TXA in intracranial hemorrhage }\end{array} \\ \begin{array}{ll}\text { Given residual uncertainty around the effects of TXA on patient- } \\ \text { important outcomes of mortality and functional recovery, further } \\ \text { research is required. Other trials are planned or ongoing (NCT03385928, } \\ \text { NCT02625948, NCT03044184, NCT02866838,ChiCTR1900027065), and } \\ \text { wXill assist in addressing this area of uncertainty }\end{array} \\ \begin{array}{ll}\text { More evidence is required evaluating the role of enteral and low-dose } \\ \text { intravenous TXA, and the potential role of TXA as rescue therapy in } \\ \text { refractory hemorrhage }\end{array} \\ \begin{array}{l}\text { More research is needed on identifying which patients with PPH are most } \\ \text { likely to benefit from TXA. For instance, it may be more helpful in patients } \\ \text { with PPH after vaginal rather than caesarean delivery [38]. }\end{array}\end{array}$

$R C T$ randomized controlled trials; TXA tranexamic acid

Recommendation

We suggest not using high-dose IV TXA in critically ill patients with gastrointestinal bleeding (Conditional recommendation, high certainty evidence).

We make no recommendation regarding the use of low-dose IVTXA or enteral TXA in critically ill patients with gastrointestinal bleeding (No recommendation, moderate certainty evidence).

\section{Evidence summary}

Five studies, including the large HALT-IT trial [98] evaluated high-dose IV TXA ( $4 \mathrm{~g} / 24 \mathrm{~h}$ or greater) [98-102], finding no difference in mortality (RR 0.98, 95\% CI 0.881.09; RD $-0.2 \%, 95 \% \mathrm{CI}-1.1$ to 0.8 , high certainty), rebleeding (RR 0.92, 95\% CI 0.82-1.04; RD - 0.7\%, 95\% CI -1.5 to 0.3 ; high certainty), or need for surgical intervention (RR 0.91, 95\% CI 0.76-1.09; RD - 0.3\%, 95\% CI -0.8 to $0.3 \%$; high certainty). Increased rates of deep vein thrombosis (DVT) (RR 2.10, 95\% CI 1.08-3.72; RD 0.2\%, 95\% CI 0-0.6; high certainty) and pulmonary embolism (PE) (RR 1.78, 95\% CI 1.06-3; RD 0.3\%, 95\% CI 0-0.7; high certainty) as well as seizures (RR 1.73, 95\% CI 1.03-2.93, RD 0.3\%, 95\% CI 0-0.7; high certainty) were noted, though the absolute number of these events was very small.

Seven studies evaluated low-dose IV and enteral TXA, [99-106] finding a reduction in rebleeding (RR 0.5, 95\% CI $0.38-0.88$; RD $-8.1 \%, 95 \%$ CI -10.9 to $-4.1 \%$, moderate certainty) and need for surgical intervention (RR 0.58, 95\% CI $0.38-0.88$; RD $-6.9 \%$, 95\% CI - 10.2 to $2 \%$; moderate certainty), and possibly a reduction in mortality at longest follow up (RR 0.62, 95\% CI 0.36-1.09; RD - $2.6 \%$, $95 \% \mathrm{CI}-4.4$ to 0.6 , moderate certainty); however, these results are limited by imprecision.

\section{Justification}

There is high certainty of harms with use of high-dose IV TXA and no clear benefit with its general use in gastrointestinal hemorrhage. Though the subgroup analysis suggests low-dose/enteral TXA may be helpful, the included studies are small and results imprecise; furthermore data on potential harms (DVT, PE, seizure) were not reported in most of these trials. While the quality of evidence for critical outcomes was moderate, the panel judged that the lack of data on the potential adverse effects of TXA in GI bleeding, especially in light of the harms seen in the HALT-IT trial, were insufficient to make a recommendation for or against the use of lower dose or enteral TXA until more data are available.

\section{Implementation issues}

There may be a role for "rescue" TXA in patients with massive exsanguination or refractory hemorrhage, for whom the risk of death due to bleeding is very high unless hemostasis is achieved, as the risk of increased seizures and VTE would be less important. If used as rescue, lower doses than those used in the HALT-IT trial may reduce the risk of these complications, as these were not observed in trials evaluating lower doses of IV TXA $(<4 \mathrm{~g} \mathrm{IV} / 24 \mathrm{~h})$.

\section{Recommendation}

We suggest the early use of TXA in critically ill patients with postpartum hemorrhage (Conditional recommendation, high certainty).

\section{Evidence summary}

Two RCTs evaluating the use of TXA for postpartum hemorrhage $[107,108]$ found a small reduction in risk of death from hemorrhage (RR 0.81, 95\% CI 0.65-1; RD - 0.4\%, 95\% $\mathrm{CI}-0.7$ to 0 , high certainty) with no effect on overall mortality (RR 0.88, 95\% CI 0.54-1.05; RD - 0.3\%, 95\% CI - 0.7 to 0.1 ; high certainty) or hysterectomy (RR $0.93,95 \% \mathrm{CI}$ $0.46-1.89$; RD $-0.2 \%, 95 \% \mathrm{CI}-1.9$ to 3.1 ; high certainty).

\section{Justification}

TXA may reduce deaths due to hemorrhage in critically ill patients with postpartum hemorrhage, without 
an impact on all-cause mortality. The absolute mortality effect of TXA in patients with post partum heamorrhage $(\mathrm{PPH})$ is small $(<1 \%)$, but may be higher in the subset of women who are critically ill. Despite the very small size of the effect, given the young age and generally high baseline health status of these patients, even a small potential reduction in mortality is desirable, especially given the high certainty that TXA has minimal harmful effects, and its low cost and high acceptability by clinicians and patients.

\section{Implementation issues}

Low-dose TXA, $1 \mathrm{~g}$ IV, should be given as early as possible if there are concerns that the patient may have significant PPH or signs of shock, as data from WOMAN indicate that TXA is most likely to be helpful within $3 \mathrm{~h}$ of onset of bleeding [107].

\section{Recommendation \\ We recommend the use of TXA in critically ill patients with bleeding post-cardiac surgery (Strong recommendation, high certainty).}

\section{Evidence summary}

Numerous RCTs have evaluated dosing strategies of TXA, summarized in a recent systematic review, including the largest trial by Myles et al. [109]. TXA had no effect upon mortality (RR $0.75,95 \%$ CI $0.5-1.13$; RD $0.3 \%, 95 \% \mathrm{CI}-0.6$ to 0.2 ; high certainty), but slightly lowered the amount of bleeding (MD - $268 \mathrm{~mL}, 95 \%$ $\mathrm{CI}-315 \mathrm{~mL}$ to $-222 \mathrm{~mL}$, high certainty), resulting in a reduction in the need for surgical intervention (RR 0.53, 95\% CI 0.4-0.71; RD - 1.7\%, 95\% CI - 2.2 to -1.1 , high certainty) and transfusion (RR 0.67, 95\% CI 0.6-0.74; RD - 16.3\%, 95\% CI -19.7 to -12.8 , high certainty), but a small increased risk of seizure (RR 4.11, 95\% CI 1.4411.72; RD 0.4\%, 95\% CI 0.1-1.5; high certainty).

\section{Justification}

There is high certainty that TXA reduces the volume of bleeding, need for surgery, and transfusion risk in bleeding patients' post-cardiac surgery; the reduced risk of reoperation is likely of major significance to most patients. While there is an increased risk of seizures, this is small $(<1 \%)$ and likely dose-dependent, with low incidence if given in low $(<4 \mathrm{~g} / 24 \mathrm{~h})$ doses. The panel judged that almost all patients would trade a reduced risk of reoperation and transfusion for this small increase, especially as the risk is likely smaller when TXA is given in lower doses.

\section{Implementation issues}

Given the risk of seizures with higher dose TXA, clinicians should aim to keep cumulative doses below $50 \mathrm{mg} /$ $\mathrm{kg}$, and exercise caution should be used before given TXA to patients with a known history of seizures and/or renal failure. Clinicians caring for patients with critically ill patients bleeding after cardiac surgery should evaluate the dose and timing of TXA given in the operating room to ensure that higher doses are not given.

\section{Discussion}

This international guideline provides guidance for clinicians caring for critically ill patients with massive and non-massive bleeding. The taskforce generated 26 clinical practice recommendations (2 strong recommendations, 13 conditional recommendations, 11 no recommendation), and identified 11 PICOs with insufficient evidence to make a recommendation as factors such as clinical effects, certainty of evidence, resource use, variation in patient and clinician values, and acceptability and feasibility of implementation were too varied to result in a consensus recommendation. A summary of recommendations can be found in Table 1, and identified research priorities in Table 2.

The strengths of this guideline include the breadth of expertise of the TF and rigorous GRADE methodology adherence. However, the guideline is not without limitations. First, the search was completed in September 2019, and ideally would be updated every 2 years. In light of the global pandemic, the completion of the guideline was delayed. Second, our systematic reviews were not registered a priori, as we adopted a rapid systematic review approach common in guideline methodology. Lastly, we did not have patient representation on the TF (Table 3).

In general, the evidence supporting transfusion practice in patients with massive or non-massive bleeding does not provide high certainty of effects for many outcomes. Current practice is often driven by transfusion thresholds which are based upon physiologic extrapolation and confounded observational evidence. For instance, although there are numerous studies evaluating transfusion ratios in massive hemorrhage, we were only able to identify two RCTs, which demonstrated more modest findings than the observational evidence, and no RCTs evaluating transfusion ratios outside of the trauma population, despite the widespread practice of incorporating highratio transfusion into hospital massive transfusion protocols. Given the large number of lives lost and resources spent caring for critically ill patients with bleeding, there is an urgent need for high-quality evidence to guide clinicians. In addition, many studies evaluated specific subpopulations of critically ill patients, resulting in gaps in areas where the task force did not believe extrapolation 


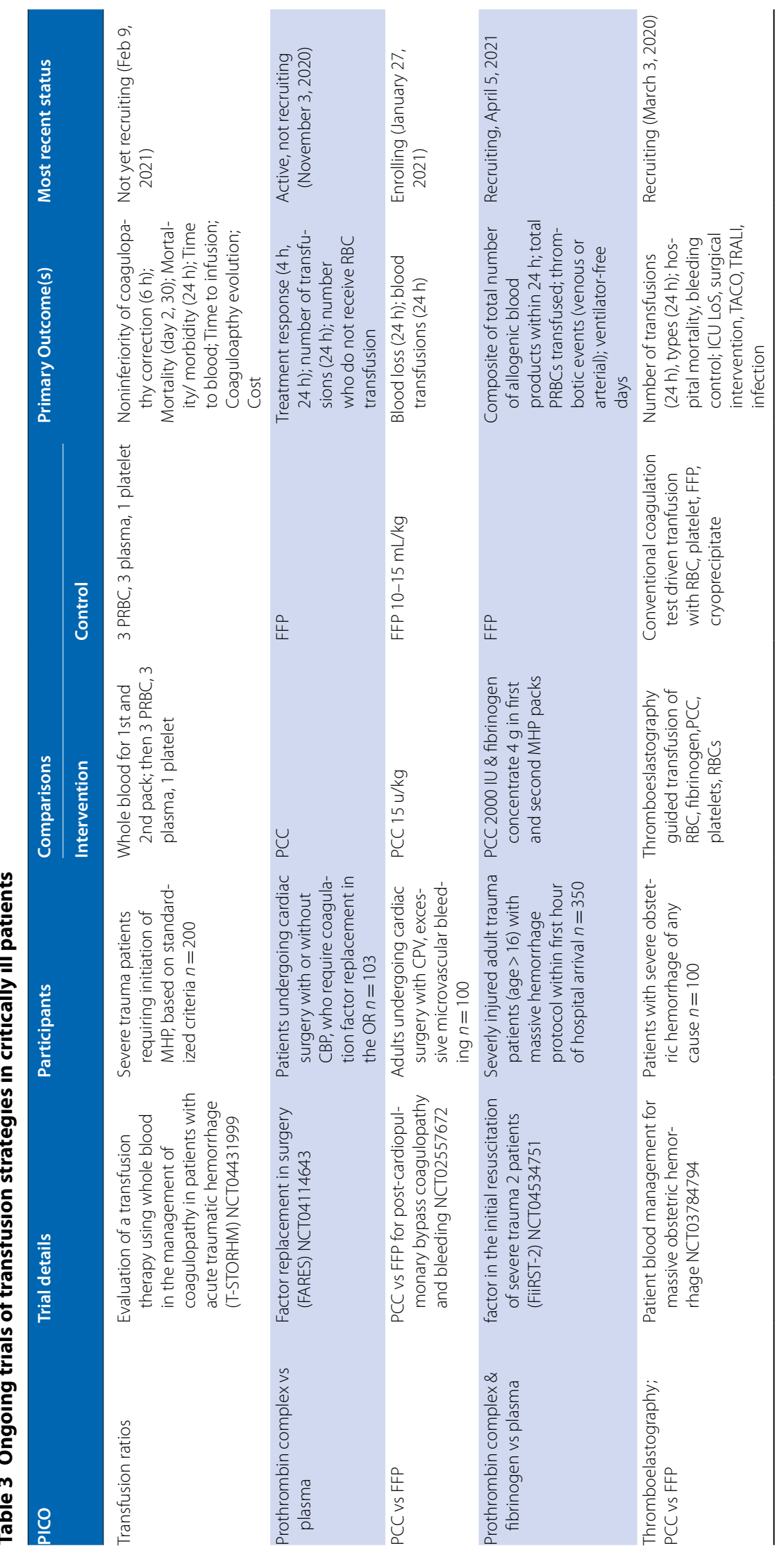




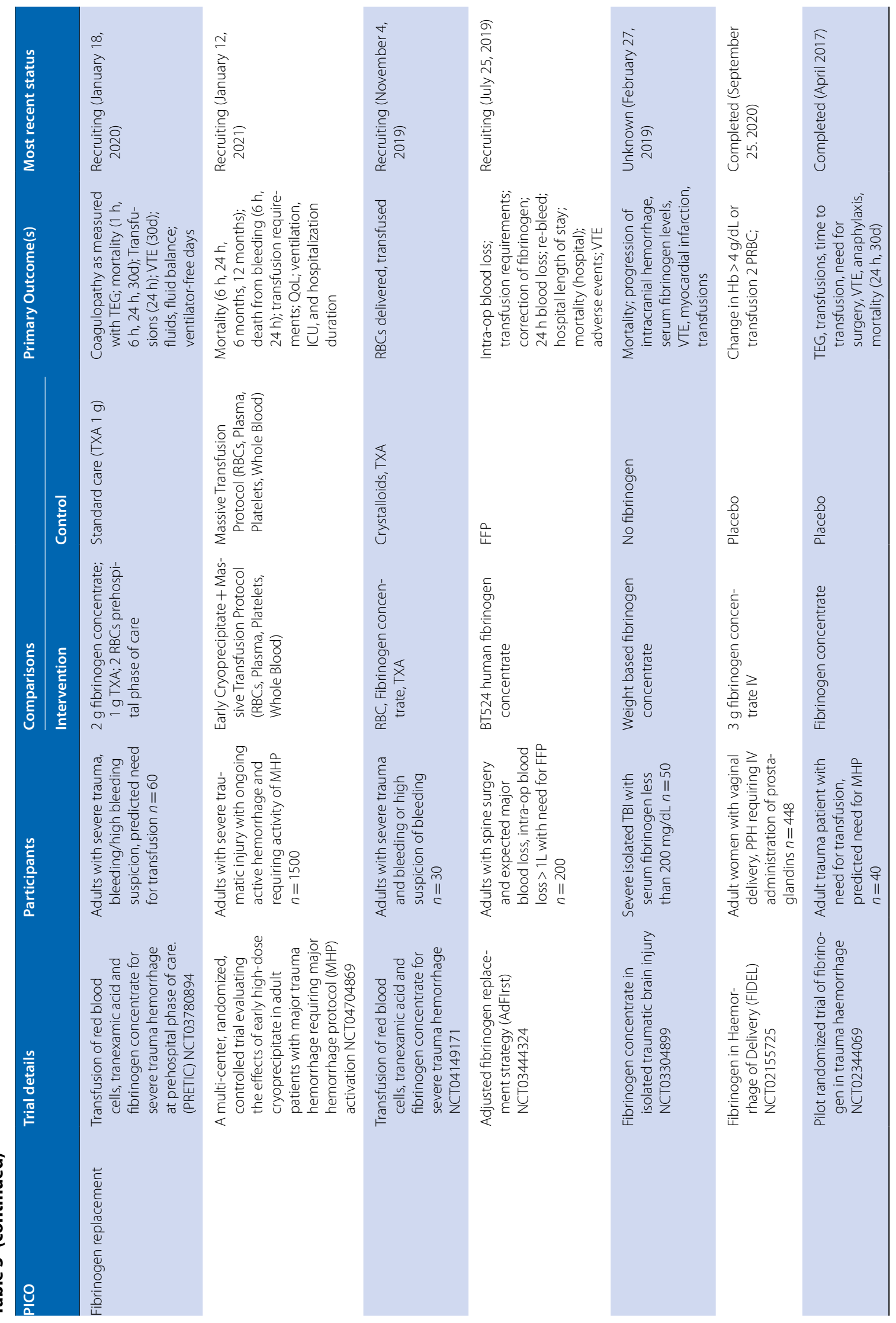




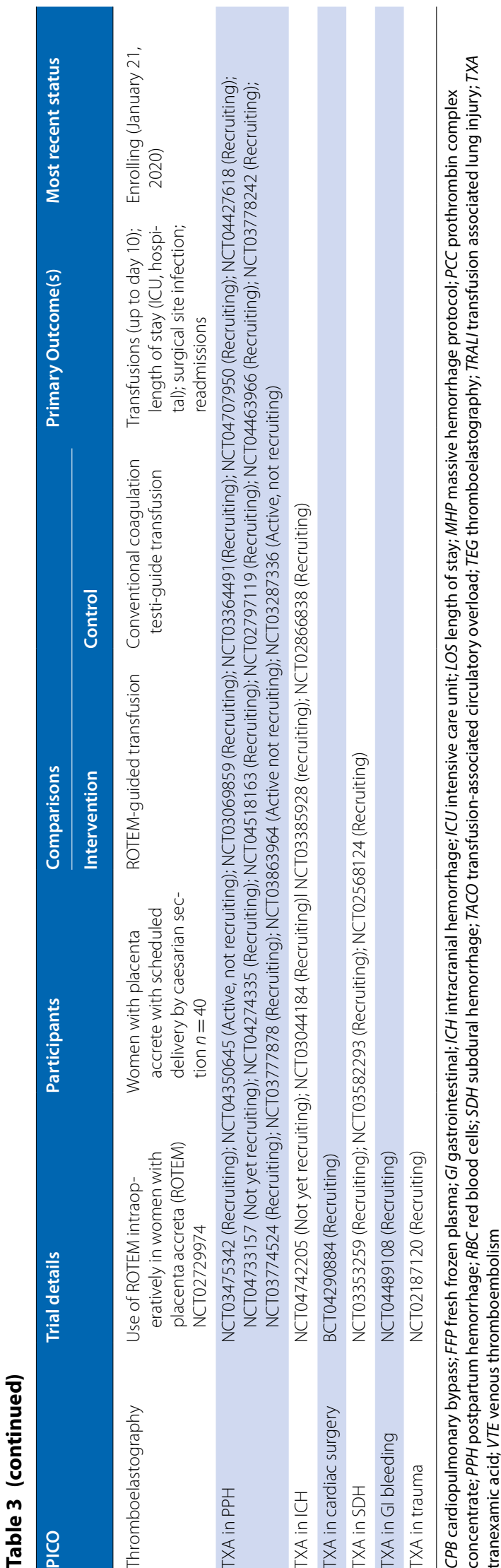

of indirect evidence to develop a general recommendation was justified.

\title{
Conclusions
}

This clinical practice guideline provides a summary of evidence and clinical guidance for transfusion in critically ill patients with massive and non-massive bleeding and identifies areas where further research is needed.

\section{Supplementary Information}

The online version contains supplementary material available at https://doi. org/10.1007/s00134-021-06531-x.

\begin{abstract}
Author details
'Department of Intensive Care Medicine, Amsterdam UMC, Location AMC, Room, C3-430, Meibergdreef 9, 1105 AZ Amsterdam, The Netherlands. ${ }^{2}$ Department of Medicine, McMaster University, Hamilton, Canada. ${ }^{3}$ The Guidelines in Intensive Care Development and Evaluation (GUIDE) Group, He Research Institute St. Joseph's Healthcare Hamilton, Hamilton, Canada. ${ }^{4}$ Department of Health Research Methods, Evidence, and Impact, McMaster University, Hamilton, Canada. ${ }^{5}$ Department of Anaesthesiology, Amsterdam UMC, Location AMC, Amsterdam, The Netherlands. ${ }^{6}$ Department of Anaesthesiology and Intensive Care Medicine, Fondazione Policlinico Universitario A.Gemelli IRCCS, Rome, Italy. ${ }^{7}$ Istituto di Anaesthesiology e Rianimazione Università Cattolica del Sacro Cuore, Rome, Italy. ${ }^{8}$ Department of Intensive Care Medicine, Centre Hospitalier Régional et Universitaire de Brest, site La Cavale Blanche, Université de Bretagne Occidentale, Brest, France. ${ }^{9}$ Department of Anaesthesia and Intensive Care, Hôpitaux Universitaires Paris Sud (HUPS), Le Kremlin-Bicêtre, France. ${ }^{10}$ Laboratory of Experimental Intensive Care and Anesthesiology, Amsterdam University Medical Center, Amsterdam, The Netherlands. ${ }^{11}$ OLVG Hospital, Amsterdam, The Netherlands. ${ }^{12}$ Department of Anesthesiology and Critical Care Medicine, Faculty of Medicine, Kepler University, Linz, Austria. ${ }^{13}$ NIHR Leicester Biomedical Research Centre-Cardiovascular, Department of Cardiovascular Sciences, College of Life Sciences, University of Leicester, Leicester, UK. ${ }^{14}$ Department of Anesthesiology, Intensive Care and Perioperative Medicine, Hamad Medical Corporation, Doha, Qatar. ${ }^{15}$ Division of Pulmonary, Critical Care, and Sleep Medicine, University of New Mexico School of Medicine, Albuquerque, USA. ${ }^{16}$ Department of Anaesthesiology and Intensive Care Medicine, AUVA Trauma Centre Salzburg, Academic Teaching Hospital of the Paracelsus Medical University, Salzburg, Austria. ${ }^{17}$ Ludwig Boltzmann Institute for Experimental and Clinical Traumatology, AUVA Trauma Research Centre, Vienna, Austria. ${ }^{18}$ Thrombosis and Haemophilia Centre, Guys \& St Thomas' NHS Foundation Trust, London, UK. ${ }^{19}$ Department of Anaesthesia and Intensive Care Medicine, Humanitas Clinical and Research Centre-IRCCS, Rozzano, MI, Italy. ${ }^{20}$ Humanitas University, via Rita Levi Montalcini, Pieve Emanuele, Milan, Italy. ${ }^{21}$ Division of Gastroenterology, McMaster University, Hamilton, ON, Canada.
\end{abstract}

\section{Acknowledgements}

The Guidelines in Intensive Care Development and Evaluation (GUIDE) group provided methodological support throughout the guideline development process. We also thank Gordon Guyatt for his mentorship.

\section{Declarations}

\section{Conflicts of interest}

None.

\section{Open Access}

This article is licensed under a Creative Commons Attribution-NonCommercial 4.0 International License, which permits any non-commercial use, sharing, adaptation, distribution and reproduction in any medium or format, as long as you give appropriate credit to the original author(s) and the source, provide a link to the Creative Commons licence, and indicate if changes were made. The images or other third party material in this article are included in the article's Creative Commons licence, unless indicated otherwise in a credit line to the 
material. If material is not included in the article's Creative Commons licence and your intended use is not permitted by statutory regulation or exceeds the permitted use, you will need to obtain permission directly from the copyright holder. To view a copy of this licence, visit http://creativecommons.org/licen ses/by-nc/4.0/.

\section{Publisher's Note}

Springer Nature remains neutral with regard to jurisdictional claims in published maps and institutional affiliations.

\section{Received: 13 July 2021 Accepted: 4 September 2021}

Published online: 22 October 2021

\section{References}

1. Lauzier F, Arnold DM, Rabbat C, Heels-Ansdell D, Zarychanski R, Dodek P, Ashley BJ, Albert M, Khwaja K, Ostermann M, Skrobik Y, Fowler R, McIntyre L, Nates JL, Karachi T, Lopes RD, Zytaruk N, Finfer S, Crowther M, Cook D (2013) Risk factors and impact of major bleeding in critically ill patients receiving heparin thromboprophylaxis. Intensive Care Med 39:2135-2143

2. Russell L, Haase N, Perner A (2018) Prediction of bleeding by thromboelastography in ICU patients with haematological malignancy and severe sepsis. Blood Coagul Fibrinolysis 29:683-688

3. Russell L, Holst LB, Kjeldsen L, Stensballe J, Perner A (2017) Risks of bleeding and thrombosis in intensive care unit patients with haematological malignancies. Ann Intensive Care 7:119

4. Pham HP, Shaz BH (2013) Update on massive transfusion. Br J Anaesth 111(Suppl 1):i71-82

5. de Bruin S, Scheeren TWL, Bakker J, van Bruggen R, Vlaar APJ, Cardiovascular Dynamics S, Transfusion Guideline Task Force of the E (2019) Transfusion practice in the non-bleeding critically ill: an international online survey-the TRACE survey. Crit Care 23:309

6. Vlaar AP, Oczkowski S, de Bruin S, Wijnberge M, Antonelli M, Aubron C, Aries P, Duranteau J, Juffermans NP, Meier J, Murphy GJ, Abbasciano R, Muller M, Shah A, Perner A, Rygaard S, Walsh TS, Guyatt G, Dionne JC, Cecconi M (2020) Transfusion strategies in non-bleeding critically ill adults: a clinical practice guideline from the European Society of Intensive Care Medicine. Intensive Care Med. https://doi.org/10.1007/ s00134-019-05884-8

7. Guyatt GH, Oxman AD, Vist GE, Kunz R, Falck-Ytter Y, Alonso-Coello P Schunemann HJ, Group GW (2008) GRADE: an emerging consensus on rating quality of evidence and strength of recommendations. BMJ 336:924-926

8. Guyatt GH, Oxman AD, Kunz R, Atkins D, Brozek J, Vist G, Alderson P Glasziou P, Falck-Ytter Y, Schunemann HJ (2011) GRADE guidelines: 2 Framing the question and deciding on important outcomes. J Clin Epidemiol 64:395-400

9. Ouzzani M, Hammady H, Fedorowicz Z, Elmagarmid A (2016) Rayyan: a web and mobile app for systematic reviews. Syst Rev 5:210

10. Higgins JP, Thomas J, Chandler J, Cumpston M, Li T, Page MJ, Welch VA (2019) Cochrane handbook for systematic reviews of interventions. John Wiley \& Sons, New Jersey

11. Peterson J, Welch V, Losos M, Tugwell P (2011) The Newcastle-Ottawa scale (NOS) for assessing the quality of nonrandomised studies in metaanalyses. The Newcastle-Ottawa scale (NOS) for assessing the quality of nonrandomised studies in meta-analyses. Ottawa Hospital Research Institute, Ottawa City

12. Manager R (2014) Book version 5.4. The Nordic Cochrane Centre, The Cochrane Collaboration, Copenhagen

13. Cornell JEMC, Localio R, Stack CB, Meibohm AR, Guallar E, Goodman SN (2014) Random-effects meta-analysis of inconsistent effects: a time for change. Ann Intern Med 160:267-270

14. Guyatt GH, Oxman AD, Vist G, Kunz R, Brozek J, Alonso-Coello P, Montori V, Akl EA, Djulbegovic B, Falck-Ytter Y, Norris SL, Williams JW Jr, Atkins D, Meerpohl J, Schunemann HJ (2011) GRADE guidelines: 4. Rating the quality of evidence-study limitations (risk of bias). J Clin Epidemiol $64: 407-415$
15. Guyatt GH, Oxman AD, Kunz R, Woodcock J, Brozek J, Helfand M, Alonso-Coello P, Glasziou P, Jaeschke R, Akl EA, Norris S, Vist G, Dahm P, Shukla VK, Higgins J, Falck-Ytter Y, Schunemann HJ, Group GW (2011) GRADE guidelines: 7. Rating the quality of evidence-inconsistency. J Clin Epidemiol 64:1294-1302

16. Guyatt GH, Oxman AD, Kunz R, Woodcock J, Brozek J, Helfand M, Alonso-Coello P, Falck-Ytter Y, Jaeschke R, Vist G, Akl EA, Post PN, Norris S, Meerpohl J, Shukla VK, Nasser M, Schunemann HJ, Group GW (2011) GRADE quidelines: 8. Rating the quality of evidence-indirectness. J Clin Epidemiol 64:1303-1310

17. Guyatt GH, Oxman AD, Kunz R, Brozek J, Alonso-Coello P, Rind D, Devereaux PJ, Montori VM, Freyschuss B, Vist G, Jaeschke R, Williams JW Jr, Murad MH, Sinclair D, Falck-Ytter Y, Meerpohl J, Whittington C, Thorlund K, Andrews J, Schunemann HJ (2011) GRADE guidelines 6. Rating the quality of evidence-imprecision. J Clin Epidemiol 64:1283-1293

18. Jaeschke R, Guyatt GH, Dellinger P, Schunemann H, Levy MM, Kunz R, Norris S, Bion J (2008) Use of GRADE grid to reach decisions on clinical practice guidelines when consensus is elusive. Br Med J 337:a744

19. McQuilten ZK, Crighton G, Brunskill S, Morison JK, Richter TH, Waters N, Murphy MF, Wood EM (2018) Optimal dose, timing and ratio of blood products in massive transfusion: results from a systematic review. Transfus Med Rev 32:6-15

20. Holcomb JB, Tilley BC, Baraniuk S, Fox EE, Wade CE, Podbielski JM, del Junco DJ, Brasel KJ, Bulger EM, Callcut RA, Cohen MJ, Cotton BA, Fabian TC, Inaba K, Kerby JD, Muskat P, Keeffe T, Rizoli S, Robinson BR, Scalea TM, Schreiber MA, Stein DM, Weinberg JA, Callum JL, Hess JR, Matijevic N, Miller CN, Pittet JF, Hoyt DB, Pearson GD, Leroux B, van Belle G, Group PS (2015) Transfusion of plasma, platelets, and red blood cells in a $1: 1: 1$ vs a 1:1:2 ratio and mortality in patients with severe trauma: the PROPPR randomized clinical trial. JAMA 313:471-482

21. Nascimento B, Callum J, Tien H, Rubenfeld G, Pinto R, Lin Y, Rizoli $S$ (2013) Effect of a fixed-ratio (1:1:1) transfusion protocol versus laboratory-results-guided transfusion in patients with severe trauma: a randomized feasibility trial. CMAJ 185:E583-589

22. Etchill EW, Myers SP, McDaniel LM, Rosengart MR, Raval JS, Triulzi DJ, Peitzman AB, Sperry JL, Neal MD (2017) Should all massively transfused patients be treated equally? An analysis of massive transfusion ratios in the nontrauma setting. Crit Care Med 45:1311-1316

23. Mesar T, Larentzakis A, Dzik W, Chang Y, Velmahos G, Yeh DD (2017) Association between ratio of fresh frozen plasma to red blood cells during massive transfusion and survival among patients without traumatic injury. JAMA Surg 152:574-580

24. Sinha R, Roxby D, Bersten A (2013) Experience with a massive transfusion protocol in the management of massive haemorrhage. Transfus Med 23:108-113

25. Delaney M, Stark PC, Suh M, Triulzi DJ, Hess JR, Steiner ME, Stowell CP, Sloan SR (2017) Massive transfusion in cardiac surgery: the impact of blood component ratios on clinical outcomes and survival. Anesth Analg 124:1777

26. Dutta EH, Poole AT, Behnia F, Dunn HE, Clark SM, Pacheco LD, Saade GR, Hankins GDV (2017) Hemostatic resuscitation in peripartum hysterectomy pre- and postmassive transfusion protocol initiation. Am J Perinatol 34:861-866

27. Weiniger CF, Yakirevich-Amir N, Sela HY, Gural A, loscovich A, Einav S (2018) Retrospective study to investigate fresh frozen plasma and packed cell ratios when administered for women with postpartum hemorrhage, before and after introduction of a massive transfusion protocol. Int J Obstet Anesth 36:34-41

28. Consunji R, Elseed A, El-Menyar A, Sathian B, Rizoli S, Al-Thani H, Peralta $R$ (2020) The effect of massive transfusion protocol implementation on the survival of trauma patients: a systematic review and meta-analysis. Blood Transfus 18:434-445

29. Bohonek M, Kutac D, Landova L, Koranova M, Sladkova E, Staskova E, Voldrich M, Tyll T (2019) The use of cryopreserved platelets in the treatment of polytraumatic patients and patients with massive bleeding Transfusion 59:1474-1478

30. Strandenes G, Sivertsen J, Bjerkvig CK, Fosse TK, Cap AP, Del Junco DJ, Kristoffersen EK, Haaverstad R, Kvalheim V, Braathen H, Lunde THF, Hervig T, Hufthammer KO, Spinella PC, Apelseth TO (2020) A pilot trial of platelets stored cold versus at room temperature for complex cardiothoracic surgery. Anesthesiology 133:1173-1183 
31. Arnekian V, Camous J, Fattal S, Rezaiguia-Delclaux S, Nottin R, Stephan F (2012) Use of prothrombin complex concentrate for excessive bleeding after cardiac surgery. Interact Cardiovasc Thorac Surg 15:382-389

32. Biancari F, Ruggieri VG, Perrotti A, Gherli R, Demal T, Franzese I, Dalen M, Santarpino G, Rubino AS, Maselli D, Salsano A, Nicolini F, Saccocci M, Gatti G, Rosato S, D'Errigo P, Kinnunen EM, De Feo M, Tauriainen T, Onorati F, Mariscalco G (2019) Comparative analysis of prothrombin complex concentrate and fresh frozen plasma in coronary surgery. Heart Lung Circ 28:1881-1887

33. Cappabianca G, Mariscalco G, Biancari F, Maselli D, Papesso F, Cottini M, Crosta S, Banescu S, Ahmed AB, Beghi C (2016) Safety and efficacy of prothrombin complex concentrate as first-line treatment in bleeding after cardiac surgery. Crit Care 20:5

34. Fitzgerald J, Lenihan M, Callum J, McCluskey SA, Srinivas C, van Rensburg A, Karkouti K (2018) Use of prothrombin complex concentrate for management of coagulopathy after cardiac surgery: a propensity score matched comparison to plasma. Br J Anaesth 120:928-934

35. Ortmann E, Besser MW, Sharples LD, Gerrard C, Berman M, Jenkins DP, Klein AA (2015) An exploratory cohort study comparing prothrombin complex concentrate and fresh frozen plasma for the treatment of coagulopathy after complex cardiac surgery. Anesth Analg 121:26-33

36. Akbari E, Safari S, Hatamabadi H (2018) The effect of fibrinogen concentrate and fresh frozen plasma on the outcome of patients with acute traumatic coagulopathy: a quasi-experimental study. Am J Emerg Med 36:1947-1950

37. Curry N, Foley C, Wong H, Mora A, Curnow E, Zarankaite A, Hodge R, Hopkins V, Deary A, Ray J, Moss P, Reed MJ, Kellett S, Davenport R, Stanworth S (2018) Early fibrinogen concentrate therapy for major haemorrhage in trauma (E-FIT 1): results from a UK multi-centre, randomised, double blind, placebo-controlled pilot trial. Crit Care 22:164

38. Innerhofer $\mathrm{P}$, Fries $\mathrm{D}$, Mittermayr $\mathrm{M}$, Innerhofer $\mathrm{N}$, von Langen $\mathrm{D}$, Hell T, Gruber G, Schmid S, Friesenecker B, Lorenz IH, Ströhle M, Rastner V, Trübsbach S, Raab H, Treml B, Wally D, Treichl B, Mayr A, Kranewitter C, Oswald E (2017) Reversal of trauma-induced coagulopathy using first-line coagulation factor concentrates or fresh frozen plasma (RETIC): a single-centre, parallel-group, open-label, randomised trial. Lancet Haematol 4:e258-e271

39. Nascimento B, Callum J, Tien H, Peng H, Rizoli S, Karanicolas P, Alam A, Xiong W, Selby R, Garzon AM, Colavecchia C, Howald R, Nathens A, Beckett A (2016) Fibrinogen in the initial resuscitation of severe trauma (FiiRST): a randomized feasibility trial. Br J Anaesth 117:775-782

40. Floccard B, Rugeri L, Faure A, Saint Denis M, Boyle EM, Peguet O, Levrat A, Guillaume C, Marcotte G, Vulliez A (2012) Early coagulopathy in trauma patients: an on-scene and hospital admission study. Injury 43:26-32

41. Inaba K, Karamanos E, Lustenberger T, Schöchl H, Shulman I, Nelson J, Rhee P, Talving P, Lam L, Demetriades D (2013) Impact of fibrinogen levels on outcomes after acute injury in patients requiring a massive transfusion. J Am Coll Surg 216:290-297

42. Hagemo JS, Stanworth S, Juffermans NP, Brohi K, Cohen MJ, Johansson PI, Røislien J, Eken T, Næss PA, Gaarder C (2014) Prevalence, predictors and outcome of hypofibrinogenaemia in trauma: a multicentre observational study. Crit Care 18:1-8

43. Wirtz MR, Schalkers DV, Goslings JC, Juffermans NP (2020) The impact of blood product ratio and procoagulant therapy on the development of thromboembolic events in severely injured hemorrhaging trauma patients. Transfusion 60:1873-1882

44. Moller A, Nielsen HB, Wetterslev J, Pedersen OB, Hellemann D, Winkel P, Marcussen KV, Ramsing BGU, Mortensen A, Jakobsen JC, Shahidi S (2019) Low vs high hemoglobin trigger for transfusion in vascular surgery: a randomized clinical feasibility trial. Blood 133:2639-2650

45. Prick BW, Jansen AJ, Steegers EA, Hop WC, Essink-Bot ML, Uyl-de Groot CA, Akerboom BM, van Alphen M, Bloemenkamp KW, Boers KE, Bremer HA, Kwee A, van Loon AJ, Metz GC, Papatsonis DN, van der Post JA, Porath MM, Rijnders RJ, Roumen FJ, Scheepers HC, Schippers DH, Schuitemaker NW, Stigter RH, Woiski MD, Mol BW, van Rhenen DJ, Duvekot JJ (2014) Transfusion policy after severe postpartum haemorrhage: a randomised non-inferiority trial. BJOG 121:1005-1014

46. Green L, Connolly C, Cooper TK, Cho G, Allard S (2015) Book blood transfusions in obstetrics. Royal College of Obstetricians and Gynaecologists, London
47. Mavrides E, Allard S, Chandraharan E, Collins P, Green L, Hunt BJ, Riris S, Thompson AJ (2017) Prevention and management of postpartum haemorrhage: green-top guideline no. 52. Royal College of Obstetricians and Gynaecologists, London, pp e106-e149

48. Villanueva C, Colomo A, Bosch A, Concepcion M, Hernandez-Gea V, Aracil C, Graupera I, Poca M, Alvarez-Urturi C, Gordillo J, GuarnerArgente C, Santalo M, Muniz E, Guarner C (2013) Transfusion strategies for acute upper gastrointestinal bleeding. N Engl J Med 368:11-21

49. Blair S, Janvrin SB, Mccollum CN, Greenhalgh RM (1986) Effect of early blood transfusion on gastrointestinal hemorrhage. Br J Surg 73:783-785

50. Jairath V, Kahan BC, Gray A, Doré CJ, Mora A, James MW, Stanley AJ, Everett SM, Bailey AA, Dallal H, Greenaway J, Le Jeune I, Darwent M, Church N, Reckless I, Hodge R, Dyer C, Meredith S, Llewelyn C, Palmer KR, Logan RF, Travis SP, Walsh TS, Murphy MF (2015) Restrictive versus liberal blood transfusion for acute upper gastrointestinal bleeding (TRIGGER): a pragmatic, open-label, cluster randomised feasibility trial. Lancet 386:137-144

51. Villarejo F, Rizzolo M, Lopez E, Domeniconi G, Atro G, Apezteguia C (1999) Acute anemia in high digestive hemorrhage. Margins of secruity for their handling without transfusion of red gobules. Acta Gastroenterol Latinoam 29:261-270

52. Engel-Haber E, Horev A, Chablani P, Bornstein NM, Jadhav A, Jovin TG, Reddy V, Hammer MD (2015) Aspirin response test role in platelet transfusion following intracerebral hemorrhage. Clin Neurol Neurosurg 137:12-14

53. Baharoglu MI, Cordonnier C, Salman RA-S, de Gans K, Koopman MM, Brand A, Majoie CB, Beenen LF, Marquering HA, Vermeulen M, Nederkoorn PJ, de Haan RJ, Roos YB (2016) Platelet transfusion versus standard care after acute stroke due to spontaneous cerebral haemorrhage associated with antiplatelet therapy (PATCH): a randomised, open-label, phase 3 trial. Lancet 387:2605-2613

54. Kim DY, O'Leary M, Nguyen A, Kaji A, Bricker S, Neville A, Bongard F, Putnam B, Plurad D (2015) The effect of platelet and desmopressin administration on early radiographic progression of traumatic intracranial hemorrhage. J Neurotrauma 32:1815-1821

55. Lisman T, Weeterings C, de Groot PG (2005) Platelet aggregation: involvement of thrombin and fibrin (ogen). Front Biosci 10:2504-2517

56. Bilecen S, de Groot JA, Kalkman CJ, Spanjersberg AJ, Brandon Bravo Bruinsma GJ, Moons KG, Nierich AP (2017) Effect of fibrinogen concentrate on intraoperative blood loss among patients with intraoperative bleeding during high-risk cardiac surgery: a randomized clinical trial. JAMA 317:738-747

57. Esmaeelzadeh M, Amini S, Soltani G, Abbasi Tashnizi M, Azami M (2016) Exogenous fibrinogen pertains beneficial effects in managing postcardiac surgery bleeding: a randomized clinical trial. J Cardio-Thorac Med 4:474-479

58. Morrison GA, Koch J, Royds M, McGee D, Chalmers RTA, Anderson J, Nimmo AF (2019) Fibrinogen concentrate vs. fresh frozen plasma for the management of coagulopathy during thoraco-abdominal aortic aneurysm surgery: a pilot randomised controlled trial. Anaesthesia 74:180-189

59. Rahe-Meyer N, Solomon C, Hanke A, Schmidt DS, Knoerzer D, Hochleitner G, Sorensen B, Hagl C, Pichlmaier M (2013) Effects of fibrinogen concentrate as first-line therapy during major aortic replacement surgery: a randomized, placebo-controlled trial. Anesthesiology 118:40-50

60. Rahe-Meyer N, Levy JH, Mazer CD, Schramko A, Klein AA, Brat R, Okita Y, Ueda Y, Schmidt DS, Ranganath R, Gill R (2016) Randomized evaluation of fibrinogen vs placebo in complex cardiovascular surgery (REPLACE): a double-blind phase III study of haemostatic therapy. Br J Anaesth 117:41-51

61. Ranucci M, Baryshnikova E, Crapelli GB, Rahe-Meyer N, Menicanti L, Frigiola A, Surgical Clinical Outcome RG (2015) Randomized, doubleblinded, placebo-controlled trial of fibrinogen concentrate supplementation after complex cardiac surgery. J Am Heart Assoc 4:e002066

62. Tanaka KA, Egan K, Szlam F, Ogawa S, Roback JD, Sreeram G, Guyton RA, Chen EP (2014) Transfusion and hematologic variables after fibrinogen or platelet transfusion in valve replacement surgery: preliminary data of purified lyophilized human fibrinogen concentrate versus conventional transfusion. Transfusion 54:109-118

63. Lance MD, Ninivaggi M, Schols SE, Feijge MA, Oehrl SK, Kuiper GJ, Nikiforou M, Marcus MA, Hamulyak K, van Pampus EC, ten Cate H, 
Heemskerk JW (2012) Perioperative dilutional coagulopathy treated with fresh frozen plasma and fibrinogen concentrate: a prospective randomized intervention trial. Vox Sang 103:25-34

64. Callum J, Farkouh ME, Scales DC, Heddle NM, Crowther M, Rao V, Hucke HP, Carroll J, Grewal D, Brar S, Bussieres J, Grocott H, Harle C, Pavenski K, Rochon A, Saha T, Shepherd L, Syed S, Tran D, Wong D, Zeller M, Karkouti K, Group FR (2019) Effect of fibrinogen concentrate vs cryoprecipitate on blood component transfusion after cardiac surgery: the FIBRES randomized clinical trial. JAMA. https://doi.org/10.1001/jama.2019. 17312

65. Torres LN, Chung KK, Salgado CL, Dubick MA, Torres Filho IP (2017) Lowvolume resuscitation with normal saline is associated with microvascular endothelial dysfunction after hemorrhage in rats, compared to colloids and balanced crystalloids. Crit Care 21:160

66. Chang R, Holcomb JB, Johansson PI, Pati S, Schreiber MA, Wade CE (2018) Plasma resuscitation improved survival in a cecal ligation and puncture rat model of sepsis. Shock 49:53-61

67. Kumar M, Ahmad J, Maiwall R, Choudhury A, Bajpai M, Mitra LG, Saluja V, Mohan Agarwal P, Bihari C, Shasthry SM, Jindal A, Bhardwaj A, Kumar G, Sarin SK (2020) Thromboelastography-guided blood component use in patients with cirrhosis with nonvariceal bleeding: a randomized controlled trial. Hepatology 71:235-246

68. Rout G, Shalimar GD, Mahapatra SJ, Kedia S, Garg PK, Nayak B (2020) Thromboelastography-guided blood product transfusion in cirrhosis patients with variceal bleeding: a randomized controlled trial. J Clin Gastroenterol 54:255-262

69. Gurusamy KS, Pissanou T, Pikhart H, Vaughan J, Burroughs AK, Davidson BR (2011) Methods to decrease blood loss and transfusion requirements for liver transplantation. Cochrane database of systematic reviews. John Wiley and Sons, Chichester, p CD009052

70. Smart L, Mumtaz K, Scharpf D, Gray NO, Traetow D, Black S, Michaels AJ, Elkhammas E, Kirkpatrick R, Hanje AJ (2017) Rotational thromboelastometry or conventional coagulation tests in liver transplantation: comparing blood loss, transfusions, and cost. Ann Hepatol 16:916-923

71. Gonzalez E, Moore EE, Moore HB, Chapman MP, Chin TL, Ghasabyan A, Wohlauer MV, Barnett CC, Bensard DD, Biffl WL, Burlew CC, Johnson JL, Pieracci FM, Jurkovich GJ, Banerjee A, Silliman CC, Sauaia A (2016) Goaldirected hemostatic resuscitation of trauma-induced coagulopathy: a pragmatic randomized clinical trial comparing a viscoelastic assay to conventional coagulation assays. Ann Surg 263:1051-1059

72. Meco M, Montisci A, Giustiniano E, Greco M, Pappalardo F, Mammana L, Panisi P, Roscitano C, Cirri S, Donatelli F, Albano G (2020) Viscoelastic blood tests use in adult cardiac surgery: meta-analysis, meta-regression, and trial sequential analysis. J Cardiothorac Vasc Anesth 34:119-127

73. Serraino GF, Murphy GJ (2017) Routine use of viscoelastic blood tests for diagnosis and treatment of coagulopathic bleeding in cardiac surgery: updated systematic review and meta-analysis. Br J Anaesth 118:823-833

74. Buscher H, Zhang D, Nair P (2017) A pilot randomised controlled trial of a totational thromboelastometry-based algorithm to treat bleeding episodes in extracorporeal life support: the TEM protocol in ECLS study (TEMPEST). Crit Care Resusc 19:000-000

75. Murphy GJ, Mumford AD, Rogers CA, Wordsworth S, Stokes EA, Verheyden V, Kumar T, Harris J, Clayton G, Ellis L, Plummer Z, Dott W, Serraino F, Wozniak M, Morris T, Nath M, Sterne JA, Angelini GD, Reeves BC (2017) Diagnostic amd therapeutic medical devices for safer blood management in cardiac surgery: systematic reviews, observational studies and randomised controlled trials. Program Grants Appl Res. https://doi.org/ 10.3310/pgfar05170

76. Roman MA, Abbasciano RG, Pathak S, Oo S, Yusoff S, Wozniak M, Qureshi S, Lai FY, Kumar T, Richards T, Yao G, Estcourt L, Murphy GJ (2021) Patient blood management interventions do not lead to important clinical benefits or cost-effectiveness for major surgery: a network meta-analysis. Br J Anaesth 126:149-156

77. Shakur H, Roberts I, Bautista R, Caballero J, Coats T, Dewan Y, El-Sayed H, Gogichaishvili T, Gupta S, Herrera J, Hunt B, Iribhogbe P, Izurieta M, Khamis H, Komolafe E, Marrero MA, Mejia-Mantilla J, Miranda J, Morales C, Olaomi O, Olldashi F, Perel P, Peto R, Ramana PV, Ravi RR, Yutthakasemsunt S (2010) Effects of tranexamic acid on death, vascular occlusive events, and blood transfusion in trauma patients with significant haemorrhage (CRASH-2): a randomised, placebo-controlled trial. Lancet 376:23-32

78. Collaborators CT (2019) Effects of tranexamic acid on death, disability, vascular occlusive events and other morbidities in patients with acute traumatic brain injury (CRASH-3): a randomised, placebo-controlled trial. Lancet 394:1713-1723

79. Guerriero C, Cairns J, Perel P, Shakur H, Roberts I, Collaborators CT (2011) Cost-effectiveness analysis of administering tranexamic acid to bleeding trauma patients using evidence from the CRASH-2 trial. PLOS ONE 6:e18987

80. Raza I, Davenport R, Rourke C, Platton S, Manson J, Spoors C, Khan S, De'Ath HD, Allard S, Hart DP, Pasi KJ, Hunt BJ, Stanworth S, MacCallum PK, Brohi K (2013) The incidence and magnitude of fibrinolytic activation in trauma patients. J Thromb Haemost 11:307-314

81. Collaborators CT, Roberts I, Shakur H, Afolabi A, Brohi K, Coats T, Dewan Y, Gando S, Guyatt G, Hunt BJ, Morales C, Perel P, Prieto-Merino D, Woolley $T$ (2011) The importance of early treatment with tranexamic acid in bleeding trauma patients: an exploratory analysis of the CRASH-2 randomised controlled trial. Lancet 377:1096-1101

82. Napolitano LM (2017) Prehospital tranexamic acid: what is the current evidence? Trauma Surg Acute Care Open 2:e000056

83. Lawati KA, Sharif S, Maqbali SA, Rimawi HA, Petrosoniak A, Belley-Cote EP, Sharma SV, Morgenstern J, Fernando SM, Owen JJ, Zeller M, Quinlan D, Alhazzani W, Rochwerg B (2020) Efficacy and safety of tranexamic acid in acute traumatic brain injury: a systematic review and metaanalysis of randomized-controlled trials. Intensive Care Med. https://doi. org/10.1007/s00134-020-06279-w

84. Rowell SE, Meier EN, McKnight B, Kannas D, May S, Sheehan K, Bulger EM, Idris AH, Christenson J, Morrison LJ, Frascone RJ, Bosarge PL, Colella MR, Johannigman J, Cotton BA, Callum J, McMullan J, Dries DJ, Tibbs B, Richmond NJ, Weisfeldt ML, Tallon JM, Garrett JS, Zielinski MD, Aufderheide TP, Gandhi RR, Schlamp R, Robinson BRH, Jui J, Klein L, Rizoli S, Gamber M, Fleming M, Hwang J, Vincent LE, Williams C, Hendrickson A, Simonson R, Klotz P, Sopko G, Witham W, Ferrara M, Schreiber MA (2020) Effect of out-of-hospital tranexamic acid vs placebo on 6-month functional neurologic outcomes in patients with moderate or severe traumatic brain injury. JAMA 324:961-974

85. Chandra B (1978) Treatment of subarachnoid hemorrhage from ruptured intracranial aneurysm with tranexamic acid: a double-blind clinical trial. Ann Neurol 3:502-504

86. Fodstad H, Forssell A, Liliequist B, Schannong M (1981) Antifibrinolysis with tranexamic acid in aneurysmal subarachnoid hemorrhage: a consecutive controlled clinical trial. Neurosurgery 8:158-165

87. Hillman J, Fridriksson S, Nilsson O, Yu Z, Saveland H, Jakobsson KE (2002) Immediate administration of tranexamic acid and reduced incidence of early rebleeding after aneurysmal subarachnoid hemorrhage: a prospective randomized study. J Neurosurg 97:771-778

88. Kaste M, Ramsay M (1979) Tranexamic acid in subarachnoid hemorrhage. A double-blind study. Stroke 10:519-522

89. Maurice-Williams RS (1978) Prolonged antifibrinolysis: an effective non-surgical treatment for ruptured intracranial aneurysms? Br Med J 1:945-947

90. Post R, Germans MR, Tjerkstra MA, Vergouwen MDI, Jellema K, Koot RW, Kruyt ND, Willems PWA, Wolfs JFC, de Beer FC, Kieft H, Nanda D, van der Pol B, Roks G, de Beer F, Halkes PHA, Reichman LJA, Brouwers PJAM, van den Berg-Vos RM, Kwa VIH, van der Ree TC, Bronner I, van de Vlekkert J, Bienfait HP, Boogaarts HD, Klijn CJM, van den Berg R, Coert BA, Horn J, Majoie CBLM, Rinkel GJE, Roos YBWEM, Vandertop WP, Verbaan D, Post R, Germans MR, Tjerkstra MA, Vergouwen MDI, Jellema K, Koot RW, Kruyt ND, Willems PWA, Wolfs JFC, de Beer FC, Kieft H, Nanda D, van der Pol B, Roks G, de Beer F, Halkes PHA, Reichman LJA, Brouwers PJAM, van den Berg-Vos RM, Kwa VIH, van der Ree TC, Bronner I, Bienfait HP, Boogaarts HD, Klijn CJM, van Bilzen M, Dieks HJG, de Gans K, ten Holter JBM, de Kruijk JR, Leijzer CTJM, Molenaar D, van Oostenbrugge RJ, van Pamelen J, Spaander FHM, Vermeer SE, van de Vlekkert J, Voorend JM, van den Berg R, Coert BA, Horn J, Majoie CBLM, Rinkel GJE, Roos YBWEM, Vandertop WP, Verbaan D (2021) Ultra-early tranexamic acid after subarachnoid haemorrhage (ULTRA): a randomised controlled trial. Lancet 397:112-118 
91. Roos YB, Rinkel GJ, Vermeulen M, Algra A, van Gijn J (2000) Antifibrinolytic therapy for aneurysmal subarachnoid haemorrhage. Cochrane database system reviews. John Wiley and Sons, Chichester, p CD001245

92. Tsementzis SA, Hitchcock ER, Meyer CH (1990) Benefits and risks of antifibrinolytic therapy in the management of ruptured intracranial aneurysms. A double-blind placebo-controlled study. Acta Neurochir (Wien) 102:1-10

93. van Rossum J, Wintzen AR, Endtz LJ, Schoen JH, de Jonge H (1977) Effect of tranexamic acid on rebleeding after subarachnoid hemorrhage: a double-blind controlled clinical trial. Ann Neurol 2:238-242

94. Vermeulen M, Lindsay KW, Murray GD, Cheah F, Hijdra A, Muizelaar JP, Schannong M, Teasdale GM, van Crevel H, van Gijn J (1984) Antifibrinolytic treatment in subarachnoid hemorrhage. N Engl J Med 311:432-437

95. Meretoja A, Yassi N, Wu TY, Churilov L, Sibolt G, Jeng JS, Kleinig T, Spratt NJ, Thijs V, Wijeratne T, Cho DY, Shah D, Cloud GC, Phan T, Bladin C, Moey A, Aviv RI, Barras CD, Sharma G, Hsu CY, Ma H, Campbell BCV, Mitchell P, Yan B, Parsons MW, Tiainen M, Curtze S, Strbian D, Tang SC, Harvey J, Levi C, Donnan GA, Davis SM (2020) Tranexamic acid in patients with intracerebral haemorrhage (STOP-AUST): a multicentre, randomised, placebo-controlled, phase 2 trial. Lancet Neurol 19:980-987

96. Sprigg N, Renton CJ, Dineen RA, Kwong Y, Bath PM (2014) Tranexamic acid for spontaneous intracerebral hemorrhage: a randomized controlled pilot trial (ISRCTN50867461). J Stroke Cerebrovasc Dis 23:1312-1318

97. Sprigg N, Flaherty K, Appleton JP, Al-Shahi Salman R, Bereczki D, Beridze M, Christensen H, Ciccone A, Collins R, Czlonkowska A, Dineen RA, Duley L, Egea-Guerrero JJ, England TJ, Krishnan K, Laska AC, Law ZK, Ozturk S, Pocock SJ, Roberts I, Robinson TG, Roffe C, Seiffge D, Scutt P, Thanabalan J, Werring D, Whynes D, Bath PM, Investigators T (2018) Tranexamic acid for hyperacute primary IntraCerebral Haemorrhage (TICH-2): an international randomised, placebo-controlled, phase 3 superiority trial. Lancet 391:2107-2115

98. Collaborators H-IT (2020) Effects of a high-dose 24-h infusion of tranexamic acid on death and thromboembolic events in patients with acute gastrointestinal bleeding (HALT-IT): an international randomised, double-blind, placebo-controlled trial. Lancet 395:1927-1936

99. Barer D, Ogilvie A, Henry D, Dronfield M, Coggon D, French S, Ellis S, Atkinson M, Langman M (1983) Cimetidine and tranexamic acid in the treatment of acute upper-gastrointestinal-tract bleeding. N Engl J Med 308:1571-1575

100. Engqvist A, Brostrom O, von Feilitzen F, Halldin M, Nystrom B, Ost A, Reichard H, Sandqvist S, Torngren S, Wedlund JE (1979) Tranexamic acid in massive haemorrhage from the upper gastrointestinal tract: a double-blind study. Scand J Gastroenterol 14:839-844

101. Tavakoli N, Mokhtare M, Agah S, Azizi A, Masoodi M, Amiri H, Sheikhvatan M, Syedsalehi B, Behnam B, Arabahmadi M, Mehrazi M (2018) Comparison of the efficacy of intravenous tranexamic acid with and without topical administration versus placebo in urgent endoscopy rate for acute gastrointestinal bleeding: a double-blind randomized controlled trial. United Eur Gastroenterol J 6:46-54

102. von Holstein CC, Eriksson SB, Kallen R (1987) Tranexamic acid as an aid to reducing blood transfusion requirements in gastric and duodenal bleeding. Br Med J (Clin Res Ed) 294:7-10

103. Cormack FCR, Jouhar AJ (1973) Tranexamic acid in upper gastrointestinal haemorrhage. Lancet 1:1207-1208

104. Bergqvist D, Dahlgren S, Hessman Y (1980) Local inhibition of the fibrinolytic system in patients with massive upper gastrointestinal hemorrhage. Upsala J Med Sci 85:173-178

105. Smith SR, Murray D, Pockney PG, Bendinelli C, Draganic BD, Carroll R (2018) Tranexamic acid for lower gi hemorrhage: a randomized placebo-controlled clinical trial. Dis Colon Rectum 61:99-106

106. Saidi H, Ghavami S, Mirafzal A, Sisakht MT, Sotudehnia M (2017) Role of intra-gastric tranexamic acid in management of acute upper gastrointestinal bleeding. IIOAB J 8:76-81

107. Collaborators WT (2017) Effect of early tranexamic acid administration on mortality, hysterectomy, and other morbidities in women with post-partum haemorrhage (WOMAN): an international, randomised, double-blind, placebo-controlled trial. Lancet 389:2105-2116

108. Ducloy-Bouthors AS, Jude B, Duhamel A, Broisin F, Huissoud C, KeitaMeyer H, Mandelbrot L, Tillouche N, Fontaine S, Le Goueff F, DepretMosser S, Vallet B, Susen S, Group ES (2011) High-dose tranexamic acid reduces blood loss in postpartum haemorrhage. Crit Care 15:R117

109. Myles PS, Smith JA, Painter T (2017) Tranexamic acid in patients undergoing coronary-artery surgery. N Engl J Med 376:1893 